Article

\title{
Digital Transformation and Sustainable Oriented Innovation: A System Transition Model for Socio-Economic Scenario Analysis
}

\author{
Roberto Pasqualino $^{1, *}$, Melissa Demartini ${ }^{2}$ (D) and Faezeh Bagheri ${ }^{3}$ (D) \\ 1 Global Sustainability Institute, Anglia Ruskin University, Cambridge CB1 1BG, UK \\ 2 Centre for Sustainable Supply Chain Engineering, Department of Technology and Innovation, University of \\ Southern Denmark, 5200 Odense, Denmark; med@iti.sdu.dk \\ 3 Department of Mechanical Engineering, Energetics, Management and Transportation (DIME) Polytechnic \\ School, University of Genoa, 16145 Genoa, Italy; Faezeh.baagheri@edu.unige.it \\ * Correspondence: roberto.pasqualino@aru.ac.uk; Tel.: +44-754-6823-803
}

Citation: Pasqualino, R.; Demartini, M.; Bagheri, F. Digital Transformation and Sustainable Oriented Innovation: A System Transition Model for Socio-Economic Scenario Analysis. Sustainability 2021, 13, 11564. https:/ / doi.org/10.3390/su132111564

Academic Editors: António Abreu and Antonis A. Zorpas

Received: 1 July 2021

Accepted: 15 October 2021

Published: 20 October 2021

Publisher's Note: MDPI stays neutral with regard to jurisdictional claims in published maps and institutional affiliations.

Copyright: (c) 2021 by the authors. Licensee MDPI, Basel, Switzerland. This article is an open access article distributed under the terms and conditions of the Creative Commons Attribution (CC BY) license (https:// creativecommons.org/licenses/by/ $4.0 /)$.

\begin{abstract}
Sustainability and digitalization are essential duties for companies to perform in the current socio-economic landscape due to risks caused by traditional manufacturing practices, and rules imposed by stakeholders and governments. Tools that help exploring uncertain future scenarios to address such a complex challenge are of vital importance for both businesses, governments, and financial institutions. This paper presents the IN4.0-SD, a novel system dynamics model to capture the dynamic interplay of industrial innovation, inequality, and inflation. The IN4.0-SD is a closed-economy System Dynamics model composed of three agents: sustainable oriented innovation business (SOIB), digital asset supplier business (DASB), and household. DASB and SOIB are both assumed to supply one product to the economy and fundamentally differ among each other in their business models. While the sustainable oriented innovation business produces and sells capital goods making revenue out of sales, digital asset supplier detaches the concept of production from sales moving toward an intangible economy, charging for a fee licence of their tools that can be distributed via a network economy. Simulations show the level of flexibility of the model in addressing a variety of scenarios, playing at the threshold of technology development, inequality rise, massive unemployment and providing an archetype for sustainable oriented innovation and digital transformation models. The findings suggested by the model analysis are used to infer conclusions for the wider society, including implications for sustainable oriented businesses and digital transformation. These are confirmed by previous studies, around the overall trend in wealth creation for large technology firms' owners, potential impact for employment in the digital economy, and transformation for the labour market.
\end{abstract}

Keywords: sustainability-oriented innovation; digital transformation; inequality; inflation; employment; productivity; sustainable supply chain

\section{Introduction}

Sustainability and digitalization are essential duties for companies to perform in the current socio-economic landscape due to risks caused by traditional manufacturing practices, and rules imposed by stakeholders and government. As a result, an increasing number of companies around the world have invested in sustainability and digital technologies, in order to understand how several risks are impacting traditional way of doing business, the environment and quality of life [1]. The development towards digitalization brings several junctures for achieving a sustainable industrial system [2].

These challenges are summarized by the Sustainable Development Goals (SDGs) framework (United Nation, 2015) set by United Nations-this is a universal, integrated set of goals designed to address 17 key interlinked challenges on people, business, and planet. The 17 goals rely on different targets, from climate change (SDG\#13), sustainable production and consumption (SDG\#12) up to industry innovation and infrastructure (SDG\#9) just 
to mention the most business-oriented ones [3]. To achieve these goals, companies have to adopt a "corporate sustainability" view by implementing sustainable strategies and business models to lead an organizational and technical transformation impacting on diverse competitive dimensions: efficiency, productivity, and innovation. Innovation is probably one of the most important factors influencing social system change since James Watt patented the first steam engine in 1781 [4,5]. It is the main driver for productivity growth in our society, supporting exponential growth in the economy via activating a variety of self-reinforcing feedback loops of assets and knowledge accumulation, and expanding investments over time. However, no real material growth is possible in a finite planet, leading toward overshooting planetary boundaries, and being cause of anthropogenic emission, and climate change [6-8].

One answer to deal with the sustainability transition is more innovation, leading towards massive change in the structure of capital, labour organization, business model and technology [9]. The dematerialisation of physical products is merging the trends in (i) sustainability-oriented innovation (SOI) and (ii) digitization. SOI, supports systems change in terms of both organization's culture, philosophy, and values, with the purpose of establishing social and environmental benefit beside the profit [10]. The fourth industrial revolution the so-called Industry 4.0 (I4.0) consists of a digital shift of business model, strategy, product, and process, through the implementation of innovative technologies (such as artificial intelligence, big data, internet of things etc). Scholars and practitioners recognize the potential opportunities of I4.0 for a SOI development, however they also agree on the need to further study this combination as it supposes a disruptive impact on markets, business models, supply and value chains [11].

To understand the impact of SOI and the digital transformation on the current productive and economic system, we propose a theoretical system dynamics model which provide insights on Industrial Innovation, Inequality, and Inflation (IN4.0-SD). The purpose is to develop the simplest possible model that captures different combinations of interplay these variables and their interrelationships via scenario analysis. The IN4.0-SD is composed of three agents: Sustainable Oriented Innovation Business (SOIB), Digital Assets Supplier Business (DASB), and household. SOIB and DASB business are both assumed to supply one product to the economy and fundamentally differ among each other in their business model. While the SOIB produces and sells capital goods making revenue out of sales, DASB detaches the concept of production from sales moving toward an intangible economy, charging for a fee licence of their tools that can be distributed via a network economy. DASB is assumed to be a key driver for change in the assets structure in both the SOIB and DASB companies, both in terms of productivity, efficiency, and labour requirement for operations. Simulations show the level of flexibility of the model in addressing a variety of scenarios, playing at the threshold of technology development, inequality rise, massive unemployment and providing an archetype for digital transformation and impact on sustainability type of models. The model can provide a good base when applied to sustainability type scenarios when dealing with energy transitions, climate change mitigation, and socio-technical transformations.

The model results are used to promote a pragmatic, organizational change, not disruptive or radical, and to support companies in the transition towards a more digital and sustainable industrial system. The model can help evaluating "co-benefits and reduce trade-offs", and therefore mitigate the negative impacts of existing solutions or, while at the same time highlight sensitive points for synergic positive impact dynamics that amplify via self-reinforcing feedback loops. In light of the above, the IN4.0-SD provides a great deal of flexibility in its parameterization and supports a wide range of scenarios that can help address the potential roles of SOI and digital transformation in industry, as well as addressing the feedback effects on the economy as a whole, providing inputs to both inflation growth, employment and dynamics of inequality.

The paper is structured as follows: the next section depicts the state of the art related to SOI and digital transition. Section 3 explains the IN4.0-SD model structure as well as the 
building blocks of the model. Section 4 provides sensitivity and scenario analysis; Section 5 describes the key modelling insights. Discussion of the results are provided in Section 6, and Section 7 draws the conclusions from this study. Additional Appendix A describing key formulations, as well as the list of the parameters and equations are also proposed.

\section{Sustainability Oriented Innovation and Digital Transformation}

\subsection{Sustainability Oriented Innovation: Causes and Effects}

The challenge for companies is to design innovation strategies to support a wide variety of stakeholders and at the same time improve well-being in the society, deals with redistribution of resources and equality among rich and poor, and maintains key target economic variables (e.g., inflation) to stable positive levels behind these sustainability initiatives [12].

Geradts and Bocken (2019) stated that SOIs can get many forms-development of new or improved product, service, process and business model which bring benefits to the environment or the society at large [13]. Process innovation refers to the solutions adopted to improve the process goods and services [14]. It aims at improving the eco-efficiency of the company. The major focus is on cleaner production. Organization innovation refers to the reorganization of the routines and structures within firms to focus people and organization.

Like sustainability, SOI involves different dimensions [14]: (i) operational optimization"doing more with less" by taking into account regulations, eco-efficiency and greening; (ii) organizational transformation-“doing good by doing new things", by going beyond greening; (iii) systems building-“doing good by doing new things with others", by focusing on collaboration capabilities. Voegtlin and Scherer (2017) identify two classes of SOI: (i) "Innovations that avoid harming people and the planet", and (ii) "Innovations that improve conditions for people and the planet". They also highlighted the dual nature of SOIs (this is similar in SDGs too): one innovation can have a positive impact on one dimension of the triple bottom line (TBL) (or one SDG) and be harmful for another [15].

In order to help achieve sustainability, innovation is the proper means which could be adopted by two directions, ones by proposing something new and another by imposing the remarkable improvement in the current state of organization. The success of innovation is contingent on diffusing it in the market or implementing it through industrial processes [16].

SOI practices is achievable through two directions including strategic sustainable behaviour and sustainable entrepreneurship.

The former one includes three main behaviours. The first one is "reactive" behaviour which tries to provide the proper respond to the external drivers, the second one is "anticipatory" which utilizes the time initiatives to comprehend the advantage characterized by competition, and the last one is "innovation-based" [17]. The first two causes incremental innovations as they primarily react to exterior changes [18]. The radical innovation change occurs by Innovation based strategies which has high level of capability to impress the sustainable development of whole industries [19].

The analysis on sustainable entrepreneurship reveals that it strictly affects the evolution of industries part toward reinforcing the sustainability via altering the structure of market, consumption patterns and supplying the product through innovative way which restrain the environmental impact.

The fact that how much the enterprise could adopt the innovative idea for strengthening their sustainability completely depends on their innovative capacity which identifies by skills, competencies, and capabilities [20]. Klewitz and Hansen asserted that if enterprises increase the frequency of interaction with the external actors, they could involve in the innovative practices beyond the firms' level through collaboration [21].

This kind of collaboration forms the alliances. The alliances integrate the required capabilities and resources and allow firms the mutual right to use. The analysis on this context revealed two main capabilities for alliance which includes alliance proactiveness 
and alliance portfolio coordination [22]. The former one comprises a set of procedures that allow a firm to adjust its performance by figuring out and following new partners, networks, and alliances. In the context of innovation, the task of alliance proactiveness is illuminating the way of how they should look for the new alliance opportunity and how they should initiate it [23]. Leischnig and Geigenmuller (2018) declared that the striking contribution of this capability is expanding market functioning through various contingency arrangements and levels of market mobility [24].

Alliance portfolio coordination capability involves the ability to recognize combined effect and keep away from sections of commonality, to utilize areas of complementarity, and to identify mutual dependencies. This capability aims to enhance knowledge flows and information quality within the firm's existing portfolio through integrating and synchronizing of present alliances [23].

Along with the independent effect of alliance proactiveness and alliance portfolio coordination for strengthening SOI, the mutual interaction between them also creates the positive influence with respect to the SOI. For example, by utilizing the capability of portfolio, the procedure of finding new alliance through recognizing the gap among alliances will be facilitated [25]. Thus, cross-pollination among present and new alliance partners may provide evidence of high value for SOI results [22].

Inigo and Albareda (2019) conducted a comprehensive study on the way in which the three stages of innovation ((i) adaptation, (ii) expansion and (iii) transformation) impacts companies' performance while aiming at achieving sustainability. The insights stemming from their analysis showed that there exist two synergic interactions between the strategic sustainability of the firm and their level levels of dynamic capabilities towards SOI. These include path dependence and self-reinforcement each supporting and maintaining sustainability practices within organizations [26].

In order to address how the defined pathway could be adapted consistently with the nature of a system it is important to collect data and gather knowledge of the current state of the system. In fact, innovation strongly depends on the availability of knowledge [27] and the approach that effectively manages that knowledge [28]. Tura et al. (2019) applies qualitative research to investigate the challenges of utilizing sustainability knowledge to enhance SOI and propose the solutions to cope with them [29].

A crucial factor significant to the process of designing innovation is the size of the organizations and the inequality between them. Since the small and medium enterprises (SMEs) face greater restrictions in terms of skills, expertise, and resources [30], the type of their innovative activities is more complicated and less effective than those of the large enterprises [31]. To compensate for these limitations, the SMEs have to collaborate with other entities improve their effectiveness in achieving SOI. In this domain, Wu (2017) classifies SMEs adopting econometric analysis by looking at the empirical assessment on interrelationship among socially responsible supplier development, SOIs, and sustainable performance. He disclosed that when SMEs adopt SOIs in multidimensional orientation, their sustainability could be significantly meliorated [32].

Wetering et al. (2017) evaluated the role of information technology (IT) flexibility and its relationship with strengthening SOI capabilities. They suggest that IT should be treated as adaptive technology that co-evolves with organizational capabilities and acts as a facilitator for cooperation [33].

A common practice for SOI is the so called Natural Inspired Innovation (NII). NII consists of establishing sustainability and organizing research and development (R\&D) to innovate organizations and products to mimic those observed in nature. In order to identify the most influential factors on the NII implementation in the corporate context, Mead et al. (2020) used multi-criteria qualitative analysis based on six case studies that attempted to adopt NII in multiple domains. They found that the characteristics of the innovation context, decision-making units, and the innovation itself strongly affect the success of NII projects and suggest that the managers should consider the long-term perspective of investments in NII [34]. 
From a market perspective, SOI has also created competition among manufacturers that are forced to keep innovating their businesses to maintain their market share. Bustamante (2020) analysed industrial processes that adopt SOI to evaluate their impact on the market. This indicated that the process innovation not only can be helpful for external objectives such as revenue generation but also support the business owner to cover a wider scope of industry goals such as more sustainable production and consumption. On the other hand, a continuous rush toward innovating systems and business models can generate concerns and challenges from social aspect including employment and inequality. For example, higher competitiveness and productivity might be reached via replacing human labour and decision making with robots, automation, or algorithms. This can be a threat to individual freedoms and rights, with implications for societal cohesion, employment, and well-being [35].

\subsection{Socio-Economic Impact of Digital Transformation}

I4.0 and digitalization are pushing companies to evolve from existing business models towards the digital factory concept, which consists of a mix of tangible and intangible assets. Most of the I4.0 technologies are in an embryonic stage and the association of these cause new "matched technologies" which could work in a physical and digital environment. I4.0 technologies impact on business models, production paradigm and logistic operations driving various businesses to replace traditional industrial systems. The state of uncertainty in the application of these paradigms creates a complexity in the understanding of the effects of such systems. The necessity to shape industrial innovation processes is also encouraged by the fact that we are exceeding the planetary boundaries. Based on Kate Raworth's Doughnut Economy framework, we should all find balance between those boundaries, but maintaining a just society for all, taking care, among other things, of the inequality between the wealthy and the poor [36].

However, the relation between technology and sustainable development is complex. On the one hand, technologies need resources with an impact on the environment and require considerable socio technical changes. On the other hand, technologies can lead to a more resource efficient economic and production system, by reducing the stress on the environment and its effect on society. Hekkert et al. (2007) developed a framework based on different innovation functions to examine technological change. The framework relies on the most relevant processes that need to be managed to succeed in technology development and diffusion. They determined different functions of innovation systems: (i) entrepreneurial activities, (ii) knowledge development, (iii) knowledge diffusion through networks, (iv) guidance of the search, (v) market formation, (vi) resources mobilization and (vii) creation of legitimacy/counteract resistance to change [37].

Kazancoglu et al. (2021) developed a system dynamics (SD) model to understand the impacts of I4.0 on the environmental and social dimension of sustainability. The model analyses the cause effect relationships between variable and provide insights on I4.0 technologies related to productivity, $\mathrm{CO}_{2}$ emissions and social indicators such as work injuries and accidents. Particularly, the model demonstrates that the implementation of I4.0 technologies is an important factor for the transition to a sustainable business model [38]. These results are confirmed also by Li et al. (2020). They analysed if digital technologies such as IoT, cloud manufacturing, big data analytics can have a positive impact on economic and environmental dimensions. Their results show that I4.0 technologies improve quality of environmental and economic performance [39]. Companies are increasing the demand of robots, IoT, artificial intelligence and big data technologies due to their multiple advantages and capabilities (i.e., integration, interoperability, efficiency, quality and productivity) as compared to humans [40].

In this regard, it is important to underline that the sound effects on economic growth might not necessarily have a positive influence on employment at least in the short period. New technologies will drastically transform the labour market resulting in many working 
activities being automated, and therefore creating less employment than the previous industrial revolutions.

Dosi et al. (2021) investigate the controversial relation between digitalization and social impacts, and particularly on jobs. Their model consists of a two-sector economy: (i) one upstream macro sector performing R\&D activity and (ii) a downstream one, whereby capital-goods acquired from the upstream sector are used to produce goods. The two sectors are linked through innovation, indeed the upstream determine product innovation while the downstream sector provides process innovation. Results of the model demonstrate that the replacement of obsolete technologies, equipment and tools impact negatively on labour demand [41]. Finally, Prause and Günther (2019) develop an agent-based model (ABM) to analyse the innovation spread of I4.0 technologies with respect to process and product innovations, and different strategies adopted by companies. The model is calibrated and validated by using data from the German Community Innovation Survey. The ABM model captures and describe the link between company capabilities and technology. It is a decision-making tool to support companies in the choice of the proper innovation strategy [42].

\section{The IN4.0-SD Model}

The IN4.0-SD (Industrial Innovation, Inequality, and Inflation-System Dynamics) model is a closed system disequilibrium economic model composed of three main entities (DASB, SOIB, and Households) connected among each other via supply-demand requirements and financial flows. Aggregated figures emerging from the model are developed in a separate entity called Government. The model accounts for approximately 810 elements including 53 stocks, 111 flows, 410 auxiliary variables, 135 parameters, and 14 table functions. The remaining 87 elements consist of additional variables created to interconnect the entities of the model and providing the basis for network approaches for future analysis. The purpose of the model is to explore the potential impact of DAS transformation on SOI, and address concerns for labour employment, inequality and stable inflation over time.

The model is developed in the software Ventity by Ventana Systems Inc, that relies on continuous type non-linear system dynamics modelling at its core, while integrating the possibility to separate system entities as objects that can be extended with large network datasets and provide the basis for hybrid system dynamics-agent based modelling. For the purpose of this paper, every one of the three entities is considered as a single, aggregated sector. Disaggregation via networks can be considered for future developments. The IN4.0-SD in the Ventity software and the full list of equations can be found at the link https://doi.org/10.25411/aru.16821058.

\subsection{System Boundaries}

Figures 1 and 2 show the system boundaries of the IN4.0-SD as composed of the three macro-agents in from both a real and a financial perspective. Figures highlight the sources of exogenous system change from the real economy, and the simplifying assumptions in money generation via borrowing in the system.

In particular:

1. Sustainable Oriented Innovation Business (SOIB): a sector that uses capital, licenced services and labour for the production and sales of capital goods. The existence of an inventory between production and shipment is assumed. SOIB endogenously sets prices and wages, employees labour, orders and produces capital, and buys licenced services from the relative sector. This latter is assumed being a driver for both capital productivity and labour requirement of capital. Their business model relies on traditional consumption and production. Revenues is made based on the sales of products. SOIB pays labour and dividends to the Household sector, purchases capital which flows back to the SOIB sector and licences to the Digital Assets Supplier Business sector. 
2. Digital Assets Supplier Business (DASB): a sector that operates by detaching the concept of production from the concept of sales and revenue. DASB uses capital, licenced services and labour to respond to a series of open tickets from their clients to be solved to maintaining high efficiency rate and doing this free or charge. This is used to support customer service to the client needs and targets high service performance. However, the revenue is generated via the sales of licenced digital products that can be distributed at no cost and without limit of reproduction. DASB pays labour and dividends to the Household sector, purchases capital which flows back to the SOIB sector and licences to the DASB sector.

3. Household $(\mathrm{H})$ sector: a sector that behaves as final consumer for both DASB and from SOIB sectors. It manages their finances via receiving payments as labour and dividends from the other sectors and uses those to purchase output from both. $\mathrm{H}$ sector composes the demand at the real level for both SOIB and DASB sectors.

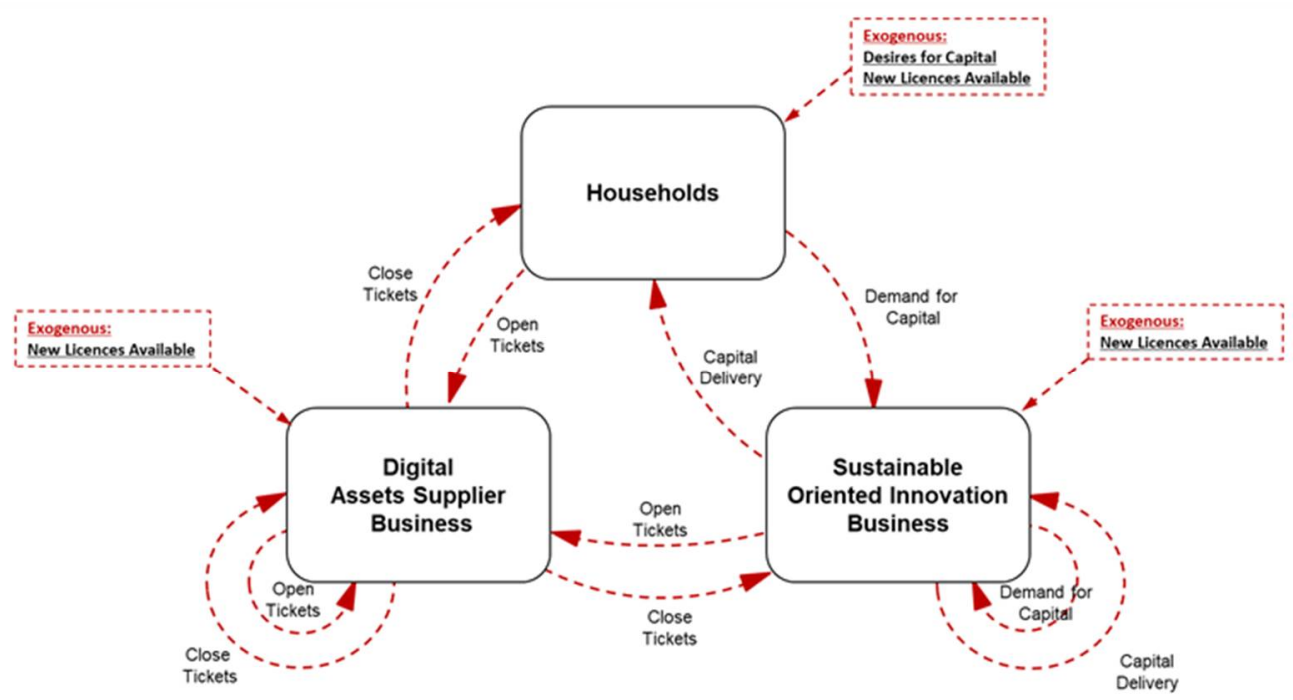

Figure 1. System boundaries and real transactions.

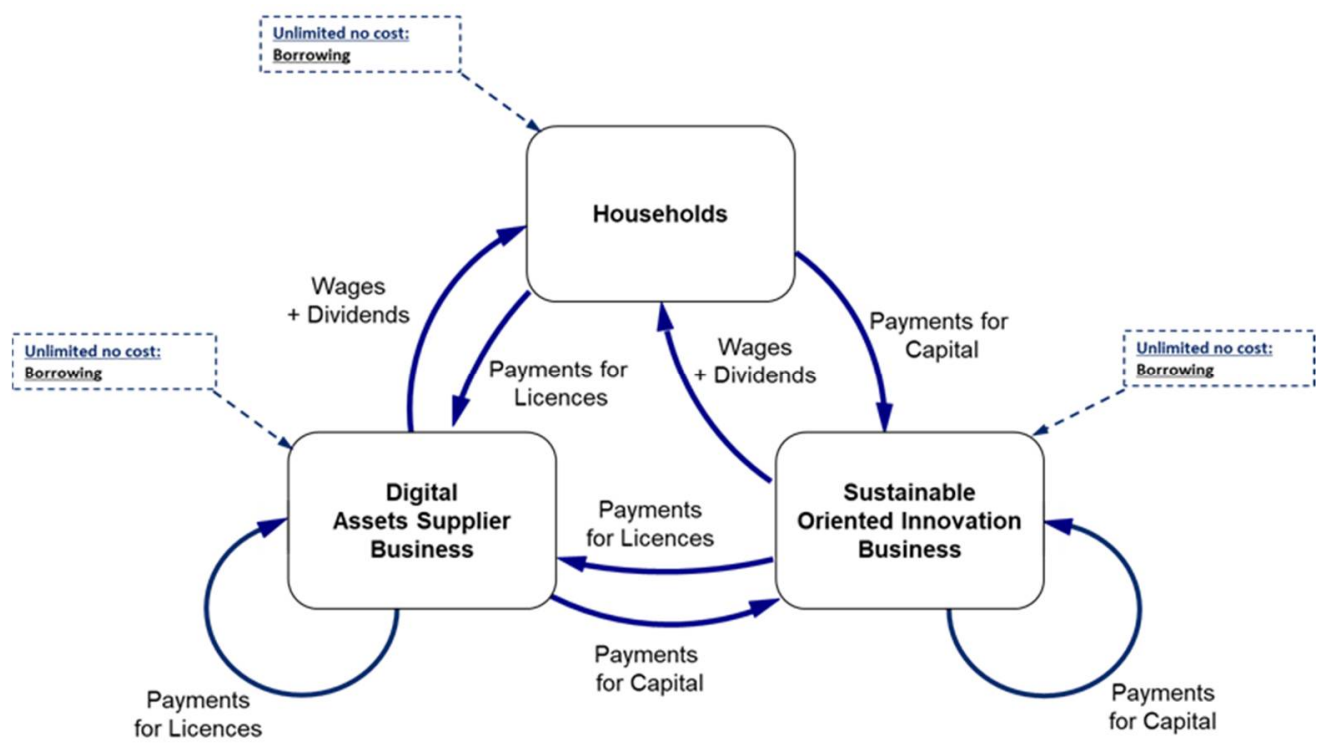

Figure 2. System boundaries and financial transactions.

\subsubsection{Key Exogenous Drivers}

As shown in Figure 1, the model accounts for two major exogenous drivers that are considered being outside the boundaries for the purpose of the model. These are: 
1. Household demand for capital: the demand for capital is dependent on a variety of factors that lie outside the boundaries of the system. These might include population change, human preferences in consumption, and so on. In IN4.0-SD household demand is assumed growing at $0.5 \%$ exponential growth rate for the duration of the simulation, despite the availability of cash can influence their ability to make purchases.

2. Availability of new digital products: it is well known that one single company can potentially create a multitude of digital products that can be licences separately, generating different revenue streams to the parent company. The IN4.0-SD does not model the creation of new products explicitly, rather it exogenously assumes these come in the form of new licences that are sold to different customers in every sector. In so doing, the three sectors assume an exogenous curve describing the new licences entering the market. With a certain time-delay, each sector would ultimately adopt those licences, supporting growth of the digital economy. These structures are explained in Appendix A of this paper.

\subsubsection{Simplifying Assumption}

As shown in Figure 2, the model assumes that cash supply adapts to whatever cash shortage in every sector, via providing cost free borrowing. This assumption is required because the system is a closed system economy that must increase the money supply to expand both in real and financial terms. The result is to simplify the model significantly in comparison to reality, while, at the same time, keep the results focused on the major points of interest that are the impact of industrial innovation on inequality and inflation.

\subsection{Model Overview}

Figure 3 shows a structural overview of both DAS and SOI entities highlighting their inputs and output that connect them with the rest of the model. For additional details on how these systems are modelled it is possible to consult Appendix A of this paper.

The entities DASB and SOIB are assumed being composed of nine sub-sectors. Seven of these are common among the two, and they differ among each other only due to the modelling of prices and their output sub-dimension, named Customer Services for DASB and Production for SOIB. The logic of the system can be explained as follows:

- Demand is collected in both entities which use extrapolative adaptive expectations to determine their level of desired output. For SOIB, demand is represented with the amount of new capital orders coming from SOIB, DASB and $\mathrm{H}$, and the desired output as the level of shipment of capital to assure demand satisfaction. For DASB, demand is intended as the open tickets generated by both SOIB and DASB. Desired output represents the Customer service rate, where, if tickets are not solved on time, the respective client might have a reduction in production rate as a lack of efficiency. This is obtained in the Production or Customer services sub-dimension as indicated in Figure 3.

- The amount of desired production is used to determine the amount of desired capital assets required to meet demand. Capital is modelled using a stock-and-flow management structure accounting for the system delays in construction and time required to organize production from the SOIB and recorded in their backlog of orders. This is calculated in the Capital sub-dimension.

- Following the Capital stock and flow structure, both Capital Productivity and Labour Requirement of Capital are calculated as a co-flow from Capital [43]. These are modelled using the same structure between the two, since it allows to stick a chosen property to the amount of Capital. In this this case we model how much output can be generated with a unit of capital, and how many workers would be required while using a certain type of Capital, and this structure allows for dynamically change those property while remaining anchored to the fundamental capital structure. The very same structure could be used to model other properties such as energy or material 
use and remains an archetype for sustainability type studies. These are calculated and in the relative sub-dimensions.

- Labour and Labour Productivity are then modelled as anchored to the available capital and the Labour requirement of capital. This is calculated in the relative sub-dimension.

- Production and customer service can be generated using the output from the subdimensions Capital, Labour, and Capital Productivity. In the process of planning output, open tickets are generated as linear proportion. Open tickets represent bugs in digital assets that might prevent a smooth operation of capital and labour. Tickets are the demand for DASB and if not solved quickly can reduce productivity of the respective client sector as well as reduce customer attractions for purchasing new licences. These are calculated in the Production and Customer Services sub-dimensions.

- Licences are representative of knowledge accumulation for companies, and thus have the effect of changing the structural composition of their assets. It is assumed that when licences do grow for a sector, then (i) their labour requirement of capital would decrease, (ii) their capital productivity would increase, and (iii) their open tickets per unit of output would decrease. Licence expansion growth is modelled as an expansion on the non-linear Bass (1969) product diffusion model [44]. In such a structure a reinforcing loop from the population of Licences in Use drives more of them from the population of Aware Potential Customers. The basic structure would generate an S-Shaped growth curve until the population of Aware Potential Customers is available. The structure had been expended by assuming that (i) licences can expire and customers face the choice of either renewing their licence at a cost or not renew it resulting in a lost customer, and (ii) a new population of Aware Customers is constantly renewed adopting an exogenous growth curve of rising $0.5 \%$ exponential growth per time unit thus allowing for rising Licence in Use for the full time of the simulation. This supports monotonic behaviour of Licences in Use growth with resulting impact on the three changing factors. This is calculated in all respective sub-dimensions.

- $\quad$ Prices is modelled in the relative sub-dimension with two different structures for SOIB and DASB. Variations of inventory level in comparison to desired level are assumed being the main determinant of price change for SOIB. For the case of DASB, given that the supply is virtually unlimited for every product, it was assumed that the market size (e.g., the sum of licences currently sold and aware potential customers) could be used as proxy for price setting. In particular, it is assumed that the larger the market size the smaller would be the price, thus allowing economies of scale and rising profits.

- Wage is modelled in the relative sub-dimension based on (i) the ability of every sector to meet their demand for labour and (ii) the trend in output generated per person. These can change based on the influence of licences on increased capital productivity and reduced labour requirement of capital, which ultimately both lead to greater productivity per worker.

- $\quad$ Cash is modelled using stock-and-flow consistency condition based on all outflows (labour payments, dividends, payments for capital, payments for licences) and inflows (revenue and borrowing). The system is initialized assuring balance equilibrium across all sectors (e.g., all revenue equals to all cash outflows for each entity) and quickly disequilibrate while assuring stock-and-flow consistency for the entire economy. The effect of cash availability are constraints to both capital and licences purchase, labour payments and dividend payments and are calculated in the respective sub-dimensions. 


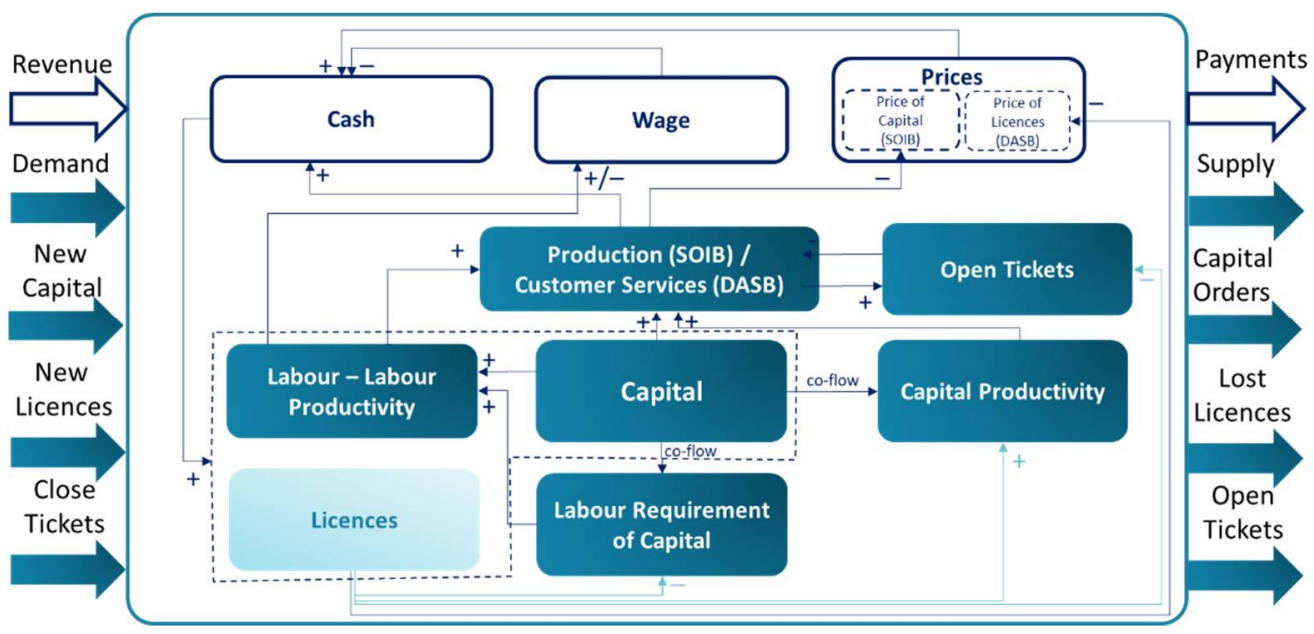

Figure 3. Overview and input output representation of DASB and SOIB.

\subsection{Model Limitations}

The model is a stylised economy model and as such does not represent significant factors of the real economy. For example, despite the variable Cash is considered explicitly in the model, and uses revenue as inflow and payments as outflow, the model ignores factors such as debt, interest rates, and cost of capital. In particular, borrowing is considered as being free of charge and supports the agents of the model to remain solvent at all the time in the simulation.

Large sectors such as banks, government, or other institutions are ignored. Also, the environmental and limits to growth factors are not considered both in terms of population change (limits to labour employment), resources and energy system change. Thus, this model represents a stylized economy that provide disequilibrium flexibility to model transition economies. The model can then be extended to wider domains to be useful in the context of global sustainability.

\section{Exploring Impact of Innovation on Inequality and Inflation}

\subsection{Time Unit, Time Horizon and Time Step}

The time unit used for model simulation had been of 1 month, and simulation time chosen to 480 months (i.e., 40 years), considered to be sufficient to capture the dynamics of system transitions and eventual tipping points. Due to time delays existing in the model, and the requirement to pass the integration test, the time step (or $\mathrm{dt}$ ) was chosen to 0.25 months (ca. 1 week). The simulation starts at time zero and runs in continuous time using Euler integration method.

\subsection{Initialization to Steady-State}

In this study, the model is simulated on generic values to demonstrate its fundamental behaviour. By adopting a more data-oriented approach these very same parameters would be initialized on datasets.

The purpose of the initialization is to assure the steady state at the start of the simulation, which means that the match in terms of both inputs and outputs in the network of entities is assured. In other words, it is required that the system respects the three following conditions:

- $\quad$ Condition 1: Production of capital from SOI matches the total demand of new capital from all three sectors;

- $\quad$ Condition 2: Solution of open tickets from DAS matches the total demand for tickets from both SOI and DAS sectors;

- Condition 3: All sectors' cash input should equal their cash output for all sectors. 
Table 1 shows the five parameters that have been set exogenously for the three sectors, and the additional four parameters that had been calculated endogenously based on the three conditions listed above starting from the exogenous ones to assure the match in all input and output in the entire model.

Table 1. Initial parameters used as foundations for all stock variables.

\begin{tabular}{|c|c|c|c|c|c|}
\hline Type & Parameter & Unit & SOI & DAS & $\mathbf{H}$ \\
\hline \multirow{5}{*}{ Exogenous } & Reference Capital addition & Capital Unit/Month & 1000 & 1000 & 9000 \\
\hline & Reference Buy Licence & Licence/Month & 5000 & 1000 & 1000 \\
\hline & Reference Tickets & Tickets/Month & 400 & 600 & NA \\
\hline & Reference Labour & Person & 1000 & 1000 & NA \\
\hline & Reference Price & $\begin{array}{c}\text { Currency unit/Capital Unit } \\
\text { (SOI)Currency unit/Licence (DAS) }\end{array}$ & 1 & 1 & NA \\
\hline \multirow{4}{*}{ Endogenous } & Reference Capital Production & Capital Unit/Month & 11,000 & NA & NA \\
\hline & Reference Sold Licences & Licence/Month & NA & 7000 & NA \\
\hline & Reference Total Tickets Service & Tickets/Month & NA & 1000 & NA \\
\hline & Reference Wage & Currency Unit/Person & 5 & 5 & NA \\
\hline
\end{tabular}

It is worth noting that the price of output of both sectors had been defined to the arbitrary value 1 at the start of the simulation, and labour is set to 1000 Persons in both SOI and DAS sectors. The Reference Capital Addition in each sector sums up to determine the Capital production in the SOIB, while the sum of Reference Tickets gives the Total Tickets to Service from the DASB. The number of Licences purchase from all sectors determines how much licences are initially sold by the DASB. These allow to calculate the starting revenue and all cash purchases from all sectors. The difference between the two corresponds to the payments to labour, which divided by the reference labour force allows to calculate Wage and assuring stock and flow consistency in the economy at the start of the simulation.

It is worth noting that without adopting this approach to initialization, the systems would still evolve towards stock and flow consistency because of its inherent structure. However, this allows for a smooth start of the model at initial conditions and set the model to go straight to the point of the purpose of this analysis.

\subsection{Choice of Arbitrary Parameters}

The IN4.0-SD includes more than one hundred parameters, that of course cannot all be tested for the purpose of the analysis. Forrester (1961) demonstrated that when systems are both complex and fundamentally uncertain, the important aspect is not to determine the value of every parameter with extreme precision, but rather seek for those fundamental highly sensitive points that can have influence to determine radical change to the dynamics of the system, thus supporting a view of system improvement [45].

In addition to this, in this study we are not using any specific data source to compare our modelling output with, making this study theoretical. Comparison to historical data can be done for future development at a later stage.

In so doing, most of the parameters influencing the system are given arbitrary values using information judgement, as typical of cases of deep uncertainty analysis. After setting the parameters the focus of the analysis shifts towards the sensitive intervention points that can radically change the system behaviour as proposed in the following section.

The parameter categories and generic values can be found in Table 2 below. Their role in the model can be described as follows:

- Elasticities: these parameters determine the impact of a change in one variable on the relative change on another variable, and their value is normally set between -1 and 1 . If an elasticity measuring the effect of variable $X$ on variable $Y$ is set at 0.1 , it means that a one unit rise in the variable $X$ would determine a $10 \%$ increase in the variable Y. Elasticities are at the core of high leverage factors in the model as explored in the sensitivity analysis in the following section. 
- Growth parameters: these are the parameters determining growth rate of variables in the system. For example, the demand of capital from households and the expansion of new licenses entering the system are set to rise at $0.5 \%$ exponential growth rate each month. The service attraction rate for new license purchase determines the number of new clients that would purchase a license due to the word-of-mouth feedback loop from existing licenses in use. A value of $15 \%$ per month indicates that each existing client would bring 0.15 clients each month, or equivalently 1 new client at every 5 months. This determines the growth rate of licenses in use in the system as driver for the entire model.

- $\quad$ Physical life of productive factors: indicate how long a particular asset will operate in a firm. For example, it is assumed that the average life of a contract for labour is 60 months (or 5 years), while capital would take 120 months (or 10 years) to discard.

- Safety stock targets: system dynamics modelling always focuses on assuring that stocks remain within realistic ranges, such as never being negative over the time of the simulation while flows can alter its value. In so doing, it is assumed that companies can form future expectations of their cash outflows based on past data, and as a result assure that the cash satisfies a certain coverage in terms of amount of time required to deplete all monetary reserves. If normal cash coverage is 6 months, it means that a firm would keep approximately 6 months' worth of monthly cash outflows as a desired cash safety measure. If cash drops below desired levels, then cash outflows can decrease in comparison to expected levels thus constraining the purchase of assets or payments of workers. Similarly, the production in the SOI entity would target to keep 12 months' worth of production in storage to remain resilient to system shocks and assure high demand satisfaction rate.

- Delivery time delay: represent the amount of time target by suppliers, and known by customers, to plan production and assure satisfaction rate. It takes time from an order of Capital or opening of a ticket for the organizations to adapt and process that specific order. The model accounts for these delays, assuming between 3 to 6 months to deliver an item after order is first made.

- $\quad$ Time for stocks' adjustment: the model accounts for the time it takes from a rational decision to transform into action accounting for things like bureaucracy, speed of institutions, time to collect data and actual action. In this model it is assumed that it takes 48 months on average to change capital, 6 months to adapt to labour requirement, and 1 month to revisit financial variables.

- Time to record change: variables such as prices and wages are assumed being dependent on their values at previous time step, and normally take time to adapt to present condition. For example, one can think that a change in labour supply might take at least one year to record a shift in wage. For simplicity, both variables are assumed taking approximately 12 months to register change out of external pressured.

- $\quad$ Time to perceive and establish trends: decision makers are assumed to adapt to past trends by extrapolating projections, and still define requirements for capacity development while anchored to past trends. This is a well-known structure used in behavioural economics [46] and System Dynamics [47] literature. For simplicity it is assumed that perception of trends might take from 3 to 12 months, and establishment of trend to lead to decisions might take from 24 to 60 months.

This set of exogenous parameters linked with the parameters used to initialize the system to steady state allow to determine the input value for every stock in the system and assure the model design can start at the desired set of values. For future research, this could make it simple to link the IN4.0 to real data.

Given that most of these parameters can be influential with minor importance in terms of system behaviour, the analysis focuses on eight high level leverage elasticity parameters bringing the effect of licences accumulation on the change of capital properties as indicated in the following section. 
Table 2. Categories of arbitrary parameters and approximative range of value setting.

\begin{tabular}{|c|c|c|}
\hline Parameter Category & Parameter Examples & Average Value \\
\hline \multirow{3}{*}{ Elasticities } & Price elasticity on inventory gap & $10 \%$ \\
\hline & Wage elasticity on labour productivity & $10 \%$ \\
\hline & Labour requirement elasticity on licences & $-30 \%$ \\
\hline \multirow{3}{*}{ Growth parameters } & Normal service attraction rate & $15 \% /$ month \\
\hline & Growth rate of licences & $0.5 \% /$ month \\
\hline & Growth rate of capital in households & $0.5 \% /$ month \\
\hline \multirow{3}{*}{ Physical life of productive factors } & Average duration of contracts & 60 months \\
\hline & Average life of capital & 120 months \\
\hline & Average time to renew licences & 6 months \\
\hline \multirow{2}{*}{ Safety stock targets } & Normal cash coverage & 6 months \\
\hline & Normal Inventory coverage & 12 months \\
\hline \multirow{2}{*}{ Delivery time delays } & Desired delivery delay for capital & 3 months \\
\hline & Normal time to solve tickets & 6 months \\
\hline \multirow{3}{*}{ Time of adjustment of stocks } & Time to adjust capital & 48 months \\
\hline & Time to adjust labour & 6 months \\
\hline & Time to adjust cash & 1 month \\
\hline \multirow{2}{*}{ Time to record change } & Time to change price & 12 months \\
\hline & Time to change wage & 12 months \\
\hline \multirow{3}{*}{ Time to perceive and establish trends } & Time to perceive inflation & 12 months \\
\hline & Time to perceive orders & 6 months \\
\hline & Time to establish trend of orders & 60 months \\
\hline
\end{tabular}

\subsection{Leverage Points for Two-Factorial Sensitivity Analysis}

Table 3 shows the considered high-leverage parameters and their range of variation for the two-factorial sensitivity analysis used in this paper. The two-factorial sensitivity analysis draws from Montgomery (2017) [48], and consists of a collection of experiments that explores all possible combinations of a series of $k$ factors that can vary on two levels each, thus resulting in $2^{\mathrm{k}}$ experiments. The choice of two levels assures the minimum possible number of simulations to provide an estimate of the mutual influence of the significant factors on system behaviour. Considering a set of $k=8$ parameters we generate $2^{8}=256$ experiments for this analysis. Supporting material to this paper proposes univariate sensitivity analysis on these same parameters for both the SOIB and DASB entities, thus exploring the possible influence of change in parameters in one entity might impact on the rest of the economy.

Six out of eight parameters test the influence of rising Licences in Use on the three levers (i) labour requirement per capital unit, (ii) capital productivity, and (iii) open tickets per job for both SOIB and DASB entities. The two levels had been chosen to reflect a range of uncertainty within those meant for the purpose of this analysis. For example, we assume that licences in use would have a negative impact of labour requirement per capital unit, and both levels for the relative elasticities have been choses within the negative range. If the elasticities were to be positive, then we would test the hypothesis that increasing licences in use could generate a rise in labour required per unit of capital. Despite this hypothesis could be tested for future analysis we opt for the former type of assumption. The same logic is applied for the impact of licences in use on open tickets per job, and capital productivity.

The other two parameters Price elasticity on market size and Price elasticity on inventory gap provide indication of the effect of endogenous system forces on prices for both sectors, that determine deflator and inflation in the model. The overarching assumption is that when demand is higher than supply, then the inventory gap would be positive, pushing SOI price up over time. On the other hand, the greater the market size of digital assets, then lower would be the required price by DASB to make profit out of it. The elasticity levels chosen for the sensitivity analysis reflect these assumptions. 
Table 3. Parameters' choice and range for two-factorial sensitivity analysis.

\begin{tabular}{lccc}
\hline Entity & Parameter & Low Level & High Level \\
\hline DASB & Price Elasticity on Market Size & -0.2 & -0.1 \\
DASB & Open Tickets per Job Elasticity on Licences in Use & -0.5 & -0.25 \\
DASB & Labour Requirement Elasticity on Licences in Use & -0.5 & -0.25 \\
DASB & Capital Productivity Elasticity on Licences in Use & 0.25 & 0.5 \\
SOIB & Price Elasticity on Inventory Gap & 0.1 & 0.2 \\
SOIB & Open Tickets per Job Elasticity on Licences in Use & -0.5 & -0.25 \\
SOIB & Open Tickets per Job Elasticity on Licences in Use & -0.5 & -0.25 \\
SOIB & Open Tickets per Job Elasticity on Licences in Use & 0.25 & 0.5 \\
\hline
\end{tabular}

The results of the sensitivity analysis can be found in the figures below. As shown in Figure 4 none of the parameters chosen for the sensitivity have impact on the number of Licences in Use adopted by both DASB and SOIB, which is mostly driven by the exogenous growth rate factors. The growth of licences in use shows well how the influence on the three entries labour requirement of capital, capital productivity, and open tickets per job. The two levels for each of the elasticities that control the influence of licences in use on the other variables are automatically visible on their two levels chosen for the sensitivity.

DAS Licences in Use

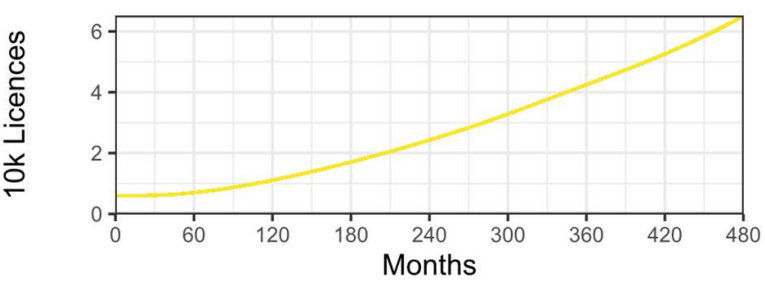

DAS Capital Productivity
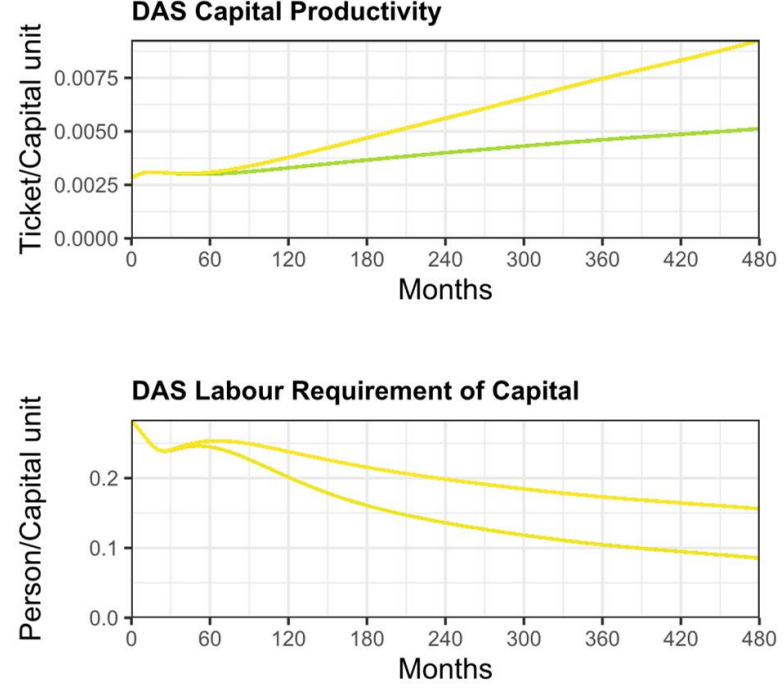

DAS Fraction of Open Tickets per Job

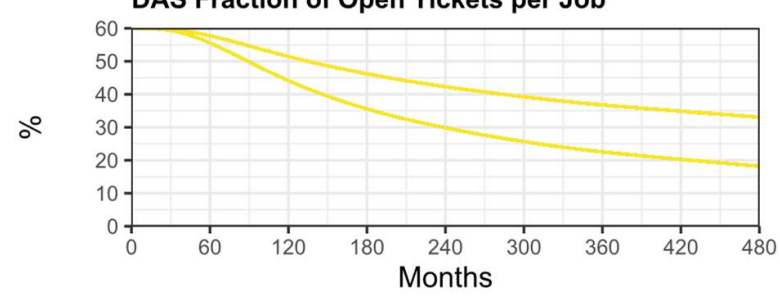

SOI Licences in Use
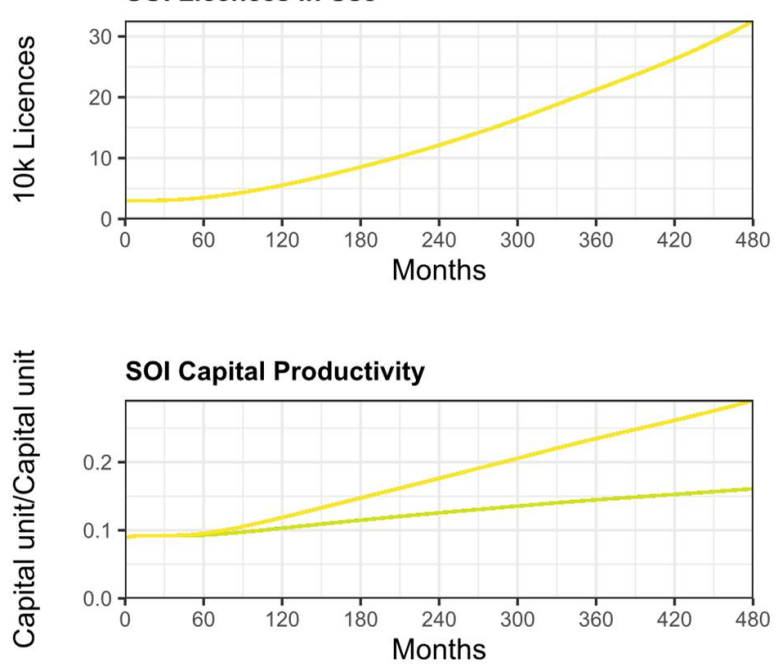

SOI Labour Requirement of Capital

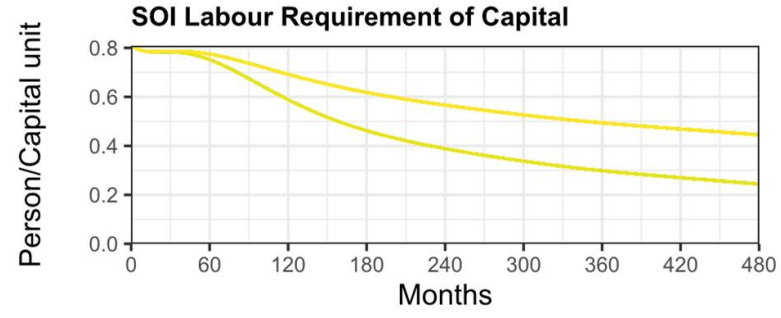

SOI Fraction of Open Tickets per Job

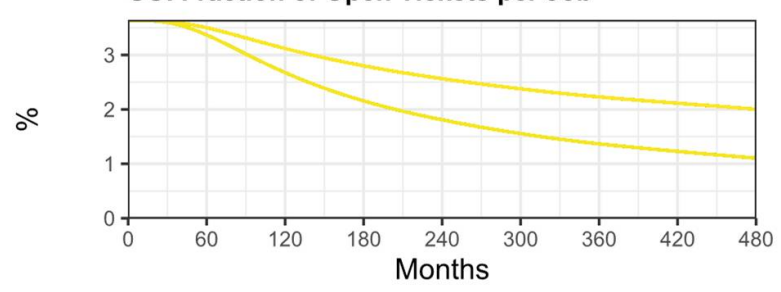

Figure 4. Input parameters for sensitivity of both DAS and SOI. 
Figure 5 shows the level of impact that the combinations of these change in parameters have on the three key variables of both DASB and SOIB, that are prices, wage, and labour force. The modelling of DAS Price is driven by licence market growth, which in the absence of change in licence in use variables shows high control capability based on the two levels of the Price Elasticity on Market Size. SOI Price results being more interesting, demonstrating how the combinations of parameter change can influence on price at different levels generating a range of scenarios, all showing rise in inflation rate.
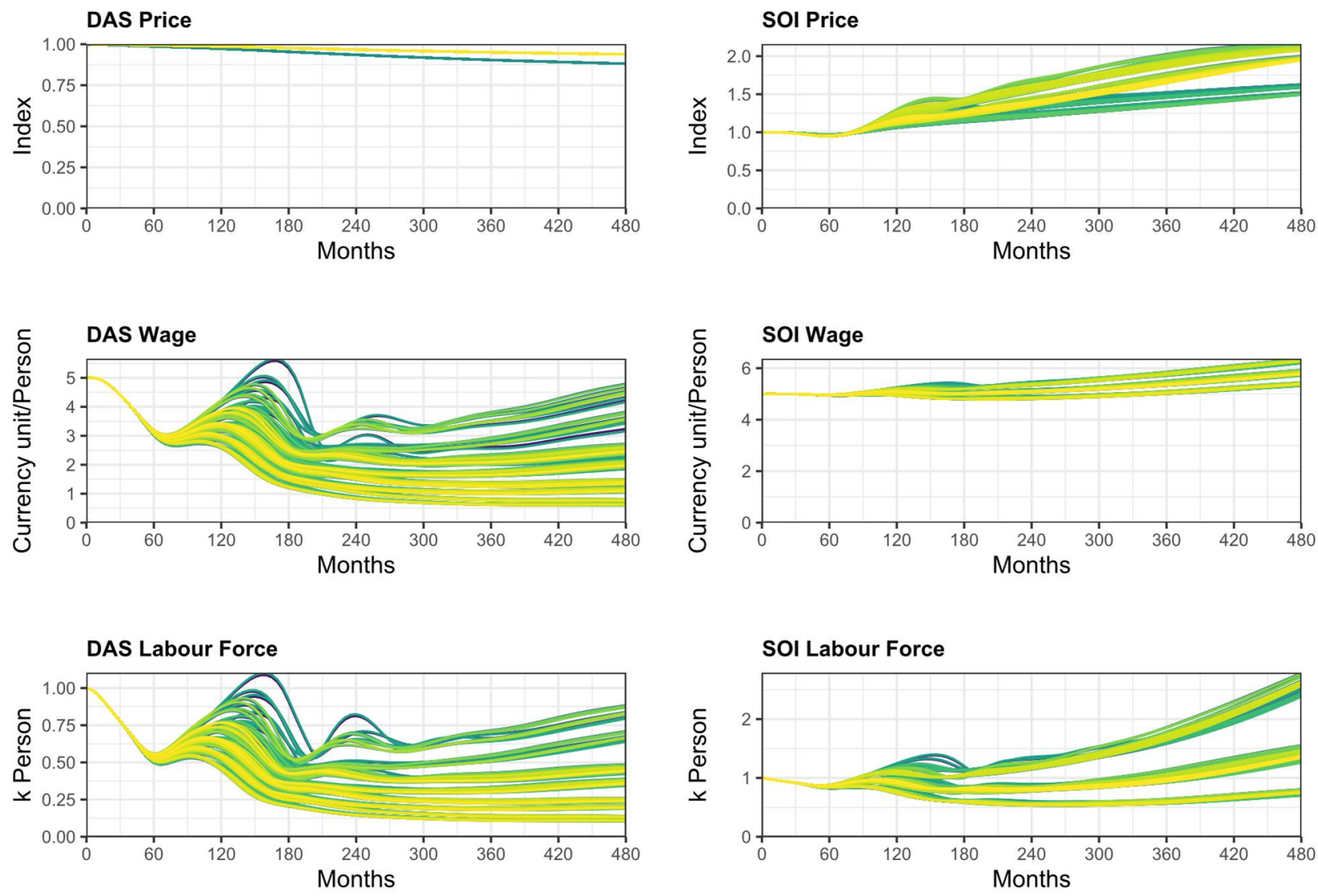

Figure 5. Sensitivity of both SOI and DAS key variables.

A large difference in the two entities behaviour can be noticed, meaning that while wage and labour force have the tendency to decrease for the digital asset supplier business, these tend to increase at different levels of growth for the sustainable oriented innovation business. This is driven by the combination of three factors. First, the effect of licences increases on increased efficiency by reducing the number of open tickets per job, has the effect of ultimately reducing the demand for workers in the DAS business. On the other hand, there is no factor endogenously decreasing the demand for capital, which tend to push for growth as driven by household consumption. Second, the constant reduction of labour requirement of capital is by itself a factor determining a dynamic decrease for labour which is contrasted to increase only by rising demand. This explains while wage tends to increase in SOIB, and why labour force results can result in growing for most sensitivity scenarios. Third, the influence of labour productivity on increasing wages plays a determinant role, particularly after the 240th month in the simulation. In other words, reduction in labour relative to increased capital productivity and constant demand would result in gaining higher wages for the those who can work, thus pushing wage up for most scenarios in the second part of the simulation.

Figure 6 shows the resulting effect of the sensitivity on aggregated variables between SOIB and DASB including the difference in cash flow income for households. As demon- 
strated by the deflator, which aggregates the price level of both productive sectors, the price rise influence in SOIB is dominant in the system to generate a final rise in inflation. This is relevant for the overarching objective of financial institution where inflation stability remains of fundamental importance. On the other hand, wage does not rise as fast as price, resulting in a growing Average price to Average wage ratio. In other words, if the parameters used for this sensitivity show some truth of an uncertain future that can be dominated mostly by machines rather than workers, then the result might be that the purchasing power of workers would gradually decrease leading them to be decreased quality of life.
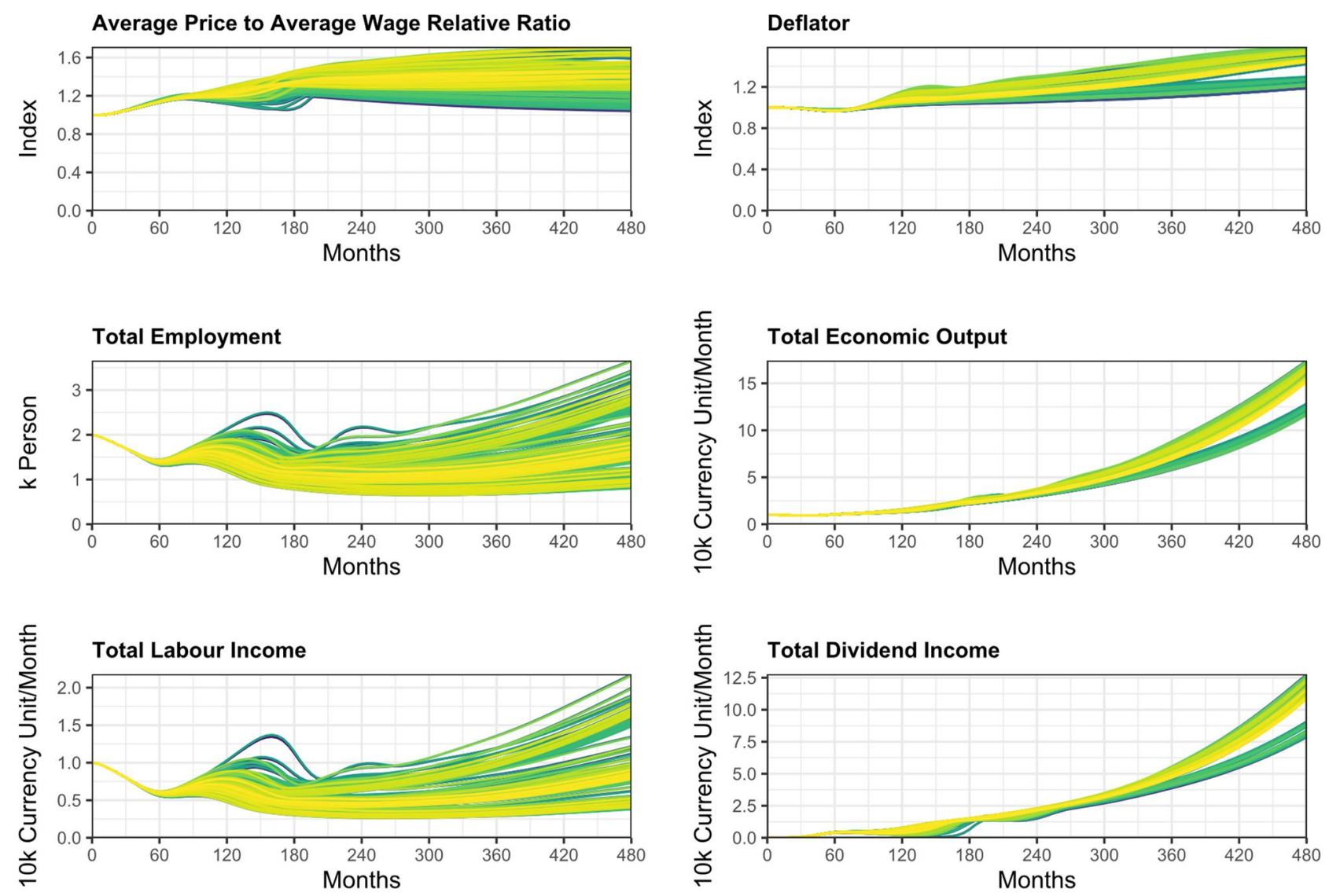

Figure 6. Sensitivity of both DAS and SOI and overall economy.

As it is possible to see the total employment and the total labour income are assumed to rise despite of the forces against their growth, and these can assure that the total economic output is still met based on standard growth targets as often set by businesses and governments. However, the wealth is shown to shift to the hands of those who own the businesses and receive dividends. It is worth noting that the variable dividend was initially set to zero (stock and flow consistency was initialized with revenue for each firm to match their purchase payment and labour payment), but while representing the profitable component of a firm, then its earnings go straight into dividends. This would potentially explain why growth would be dominated by capital owner purchases rather than workers perceiving wage, resulting in a more inequal world despite meeting the targets of inflation stability and growth.

\section{Key Modelling Insights}

The IN4.0-SD is a theoretical system model which purpose is to bring together the basic structures that can determine the influence of digital transformation on sustainable oriented economic system and inequality while targeting institutional governmental targets such as growth and inflation stability. As demonstrated in this paper, those institutions 
have a good chance of meeting their targets in the near future, despite the fact that this has profound implications for how we would run an economy, particularly by removing wage-earners from the production equation. Despite being inherently complex, the model is built on simple assumptions on the functioning of the economy which use, at current stage of development is to explore potential scenarios of the future, which might foresee a reality in the years to come.

The fundamental practical assumptions used to run this analysis can be summarized as follows:

- The digital transition is taking dominance in the real world, leading to a change in the concept of labour as we know it. It is uncertain if this effect might rise demand for labour and decrease it in absolute terms. This model is set to explore the case in which labour force would be less and less required to achieve economic output.

- Sustainable oriented innovative businesses that aim for reduction in the use of natural resources and waste, while increasing productivity, often rely on digital intangible assets to achieve their sustainability targets. This might lead to a change in the composition of labour in the system, while maintaining a profit-making purpose which favours the owners of the assets rather than the labour.

- The assumptions characterize a top-down perspective to modelling rather than focusing on micro-level behaviours of decision makers that work in organizations. This indicates that we seek to provide a general picture rather than precise estimates. Future effort to generate insights for organization structural change using the model would require more work with data and direct contact with innovative organizations.

On a theoretical level we adopt a view of the world that is in line with complexity economics, in the sense that we accept the notion that the future is uncertain, and the only thing that we know is that we do not know [49,50]. As a result, we consider a scenario analysis based on key leverage factors as more relevant for future exploration despite the little use of empirical data to inform such an analysis. On the other hand, numerical data in such are domain are difficult to retrieve, we feel that the conclusion of the analysis still hold.

It is also important to recognize that these assumptions brought together thanks to two ad-hoc defined modelling structures as explained in the supporting material. These are:

- Ad-hoc production function: the production function had been built neglecting the standard formulation as proposed in economic textbooks, such as Cobb-Douglas, Constant Elasticity of Substitution or Leontief production functions [51]. The formulation allows for a particular factor to production to drive adaptation (in this case capital) and use the other factors to determine complex adaptivity which stick to the first production factor (in this case labour and productivity). The properties of this formulation are different from those of standard formulation that often do not stick with reality [52].

- Archetype for resource use in capital vintage structure: the structures adopted to model productivity and labour requirement are equivalent among each other. Their difference lies in the positive impact of digital change on capital productivity, while assuming reduction in the requirement of labour. Such as structure can be adopted as-is for the cases of energy use, mineral uses, and material consumption in general. This could support better modelling of industrial innovation in the context of natural resource consumption.

The key outcome is that, if those assumptions about the uncertain future are true, we are likely to face a reality where financial institution targets (e.g., stable inflation) can be met thanks to technology development, despite leading to rise in inequality, rise in unemployment and prosperity of the rich. 


\section{Discussion and Implication \\ 6.1. Modelling Implications}

The IN4.0-SD model provides insights on several dimensions. It highlights the link between the increasing productivity and inflation and their impacts on wages and inequality. In agreement with Raberto et al. (2018) [5], an increasing inflation cannot be sustained in the long run, as it reduces real wages. In addition to this, as outlined by our model, the possible scenario of decreased employment caused by the increasing adoption of innovation and digital technologies (DASB), may exacerbate inequalities in favour of the wealthy who own productive assets. This is a well-known trend, from the middle of the 1980s, real wages in developed countries have not kept the pace with productivity, shifting the functional distribution of income towards profit [53].

Moreover, the predominance of DASB brings to potential issues for the employment. Indeed, our model confirms the results provided by Dosi et al. (2021) that demonstrate the negative impact of technology adoption on jobs. Without effective policies, the increase in technology eventually leads to a massive loss of unemployment and purchasing power for wages and to the collapse of the economy. Governments aim at a stable inflation growth and assure maximum possible employment to their populations. However, when innovation modifies the characteristics of the way we run our economy, it becomes important to understand the drivers that drive system change with focus on potential risks such as inequality, instability, and potential rise in unemployment.

It is worth noting that the structure proposed in the IN4.0-SD can be used as part of larger models of capital growth and integrated in the context of climate modelling and integrated assessment with ease. As a result, the simplified structure of price modelling adopted here might be not suitable for addressing great challenged in the financial system. One potential future application could be to be used as fundamental structure of the ERRE model [51] used to approach energy transition, linkages with food and finance. The ERRE is a large and more sophisticated models built upon the World3-03 [7] and earlier version of the System Dynamics National model from [54,55]. However, the ERRE still employs a standard neo-classical production function. The structure proposed in IN4.0-SD can potentially solve the limitation of the ERRE providing a step forward in the understanding of complex systems such as the global economy and its relationships with the planetary boundaries.

\subsection{Implications of Digital Transformation and Sustainable Oriented Innovations}

Technology and digital transformation influence society and the economy on various dimensions that can profoundly change every aspect of human life. Some of these changes might be pleasant, and some might not. The social implications of this research are more visible in those societies that suffer the challenges stemming from inequality because of the industry 4.0 revolution.

As a result of the advent of digitalization, an increasing number of people have relocated to cities in order to achieve a higher standard of living. Yao Lu and Feng Wang (2013) revealed that internal migration of approximately $35 \%$ of population from rural to urban areas in China has caused the change in the labour market such to establish wage differentials and barriers due to occupational structure [56].

Piore (1979) and Becker (2010) declared that besides the diversity among human capital endowments, ethnic and racial differences between the resident and immigrant people reinforce the inequality in employment [57,58]. Block and Evans (2005) and Kalev et al. (2006) demonstrated that in addition to market structure, intense market competition driven by technology advancement in each industrial sector can lead to workplace inequality $[59,60]$.

The equipment advancement following technology development has established two orientations in labour market. According to one, the equipment is so user friendly and each operator even with low level of skills could work with it. On another side, the equipment could be too advanced and working with it would require the high level of skills. Under these orientations, the job position for low skilled people with low wage as they deserved 
would increase as well as for high skilled persons with high wage. As a result, wage and employment development of medium-skilled persons lag behind that of low- and high-skilled persons, and inequality is felt more strongly by these classes of people [6].

All these circumstances could be a stimulus behind the creation of inequality in the labour market, and regulators could shed light on the direction of inequality reduction using the proposed model.

On the other side of society, it is possible to confirm that welfare is accumulating in the hands of the few, and the young owners of tech giant firms are taking dominance in a world that follows a digital transformation (Schmitd et al. 2021) [61]. To repay for the inequal distribution on income in the economy, they often engage in philanthropic organizations, with the main objective of solving global sustainability challenges. This movement was pioneered by the Bill \& Melinda Gates Foundation, and today accounting for a variety of philanthropic initiatives such as the Chan Zuckemberg Initiative, the Emerson Collective, the Omidyar Network, and Arnold Ventures. By building wealth on the digital transition they surely provide a story of good intentions, but offer only limited transparency about real motives and actions.

On the other hand, SOI and DAS businesses can also provide positive effects on environment. The challenge of climate change requires to produce with less, reducing waste and stopping using fossil fuels to run businesses. Reacting to climate change in this era demands for responses that interconnect the global community on multiple levels. These effects not only impact on the socio-geographic issues, but also on industry creating huge operational problems. Simpler ways to run businesses can be based on low material content economy, thus pushing toward a digital and service economy using business models as those outlined in this paper. In the context of SOIB, the innovation could be represented by the upgraded version of three main elements including processes, organizational interactions, and products that tries to harness the negative environmental impact, strengthen the social dimension while benefitting value creation for society [62].

Process innovation consists of proposing the new way for the producing of commodities and supplying services that uses the less raw material, limits the rate hazardous and waste, and does not contribute to climate change [63]. Organizational innovation is achievable via rearranging the interactions and formation and adopting the new orientation for managing system especially from environmental viewpoint [64] and finally product innovation could be reached by adjusting better design products to support reuse, easy recycling of its material component raw material, and extend their durability [65]. All these three main elements not only as stand-alone items, but also thought synergic interaction among each other can determine considerable level of innovation towards sustainable businesses [30].

Finally, it is fundamental to underline the primary role of decision makers. Indeed, factors such as taxes and government interventions can potentially influence the stability of the system, regulations can apply constraints to the natural evolution of systems, and these must be all considered simultaneously to reach sustainability and a zero-carbon economy as soon as possible. Policy makers can play a fundamental role amplifying or reducing these effects by means of public investments and/or tax incentives, removing legislation, technological or financial barriers through effective policy measures, leading to steady economic growth with business opportunities across the whole economy $[36,66,67]$. It is critical that policy development embraces technological advancement in a realistic way, accounting for feedback from and to the real economy as outlined by our model and a line of research of economics of energy transition and complexity [68].

\section{Conclusions}

Innovation and technology change have driven companies and countries higher wealth since the first agricultural revolution. However, such a development has led us to face global challenges such as ecological sustainability while assuring good quality of life 
to society [5]. Developing tools that can help exploring the ethical, environmental, and economic nature of the various issues related to industrial innovation is therefore vital.

This paper focuses on the role of sustainable oriented and digital asset supplier businesses by proposing the IN4.0-SD model: a complex system model built around the role of digital transformation for sustainable oriented innovative businesses and looking at fundamental socio-economic variables such as inequality, unemployment and inflation change.

Lacking structured data to compare the model results with, the model is used as a theory by accepting the notion of fundamental uncertainty $[49,50]$. The analysis is performed by investigating multiple scenarios using univariate and two-factorial sensitivity testing with the assumption that digital technologies can be used as a proxy for innovation in general, with implications for systems efficiency, labour requirements of productive assets, and productivity growth. The analysis reveals that, while the digital transformation can produce positive results in terms of inflation target stability and growth achievement, it may also be the cause of increasing inequality between the assets' owners and the workers, by lowering wages in real terms, and potentially being cause of large increase in unemployment, as other literature suggests [41].

The findings suggested by the model analysis are used to infer conclusions for the wider society, including implications for sustainable oriented businesses and digital transformation. These are confirmed by previous studies, in particular around the overall trend in wealth creation for large technology firms owners, potential impact for employment in the digital economy, and transformation for the labour market.

Next steps of this line of work can include integration of the model with data emerging from public and private sources, likely to involve case-studies and business partners. In addition to this, the proposed structures for production function and archetype to model assets properties in terms of labour requirement and productivity can be used as standalone applications to enhance the functionality of wider purposes system models. Among those, models such as the ERRE (see Pasqualino and Jones 2020) [51] an benefit from these novel ideas while linking them with both climate, agriculture, and energy systems.

Author Contributions: Conceptualization, all authors; methodology, R.P.; software, R.P.; validation, R.P.; formal analysis, R.P.; investigation, all authors; data curation, R.P.; writing-original draft preparation, all authors; writing-review and editing, all authors; visualization, R.P. All authors have read and agreed to the published version of the manuscript.

Funding: This research received no external funding.

Institutional Review Board Statement: Not applicable.

Informed Consent Statement: Not applicable.

Conflicts of Interest: The authors declare no conflict of interest.

\section{Appendix A. Model Structures}

Appendix A is supplementary to Section 3.2 of the paper by describing the system structures in terms of stocks and flows, and the fundamental relationships that determine the dynamics of the model for the entities SOIB and DASB. The IN4.0-SD in the Ventity software and the full list of equations can be found at the link https:// doi.org/10.25411 /aru.16821058.

As shown in Figure 3, both SOIB and DASB share seven similar sub-dimensions (e.g., (i) Licences, (ii) Capital, (iii) Capital Productivity, (iv) Labour Requirement of Capital, (v) Labour, (vi) Wage, (vii) Cash, and differ among each other in the modelling of (i) price, and (ii) customer services (for DASB) or production (for SOIB).

This section describes those dimensions in the following order:

- Licences;

- Capital, Capital Productivity, Labour requirement of Capital, Labour;

- Production and Customer services; 
- $\quad$ Prices and Wage;

- Cash.

\section{Appendix A.1. Licences Sub-Dimension}

Figure A1 shows a simplified stock and flow diagram of the Licences subsystem used for all the three sectors of the IN4.0-SD. This subdimension presents a reinforcing loop typical of technology diffusion (or pandemic) models, where the number of licences in use pulls larger and larger licences purchases from the stock of Aware Potential Licences Purchase. This dynamic is also constrained by the ability of DASB to supply a good service and efficiency to their customers, as well as from the availability of cash of each client sector that must comply with their finances. Licences expire at with a certain time delay, requiring either to renew that licence (thus generating additional revenue), or simply leave the product.

The dynamics of growth of this system is dependent on the continuous expansion of the Aware Potential Licences Purchase stock. Without an inflow to this stock, the overall dynamic of the system would be exponential growth and collapse. The population of new licences enters in the system as New Unaware Potential Customers based on an exogenously set curve. With a certain time-delay, customers gradually become more and more aware of the products, thus becoming Aware Potential Licences Purchase customers, and being dragged into purchases of new licences by the worth-of-mouth reinforcing loop driven by Licences in Use. The strength of the word-of-mouth reinforcing loop is dependent on the customer satisfaction ratio that can decrease if DASB business does not meet capacity requirement to assure high satisfaction rate, and the availability of cash of every sectors.

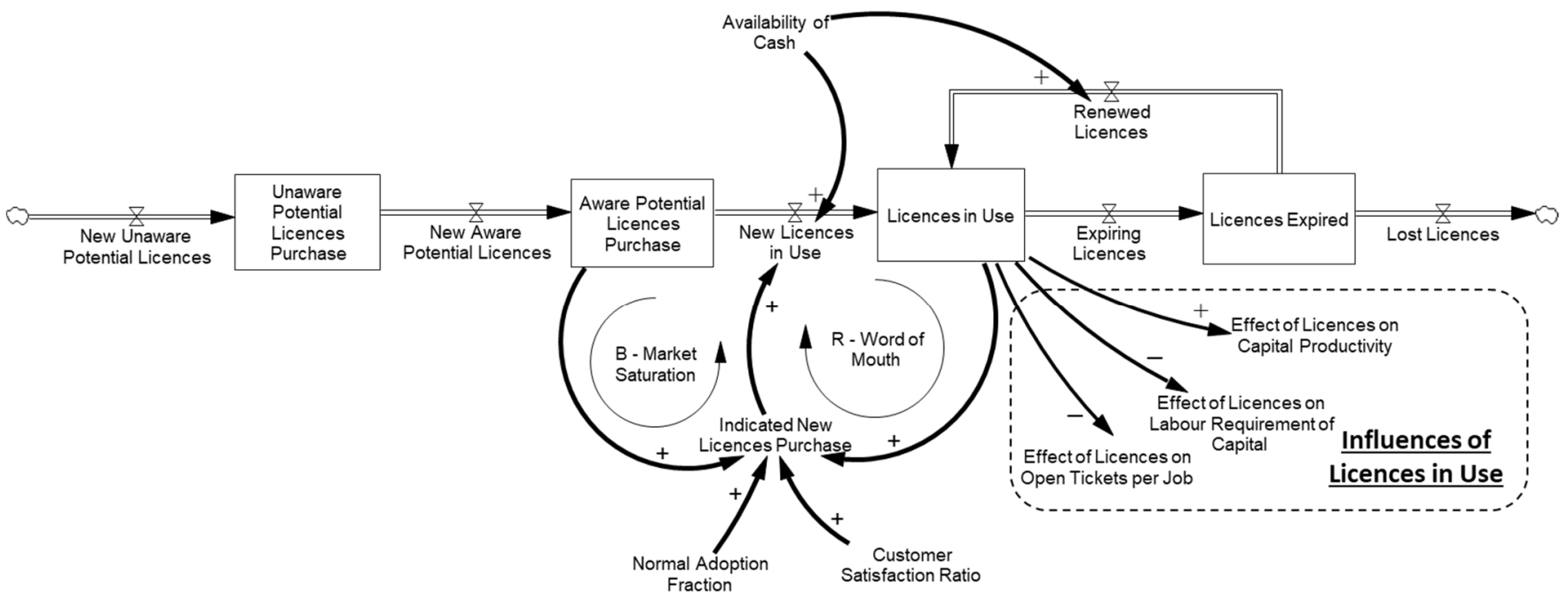

Figure A1. Licences sub-dimension for DASB, SOIB, and H sectors.

The stock Licences in Use is used here as a proxy for innovation and digital assets ownership which use influences the way firms make business. This is dependent on the three effects and elasticities which bring and increase in Licences in Use to (i) an increase in capital productivity per unit of capital, (ii) a decrease in labour requirement per unit of capital, and (iii) a decrease in open tickets per job as follows.

Desired productivity $\pi^{*}$ is calculated as:

$$
\pi^{*}=\left(\frac{\text { Lic }}{\text { Lic }_{0}}\right)^{\varepsilon_{\pi}} \times \pi_{0} \quad \text { Unit }: \frac{\text { Capital Units }}{\text { Capital Unit }} \text { or } \frac{\text { Tickets }}{\text { Capital Unit }}
$$

where $\pi_{0}$ is the capital productivity at time $0, \frac{L i c}{L i c_{0}}$ is the relative increase of licences in use in comparison to time 0, and $\varepsilon_{\pi}$ is the Capital productivity Elasticity on Licences in Use. This latter is assumed to have a value between 0 and 1 . 
Desired labour requirement of capital $\gamma^{*}$ is calculated as:

$$
\gamma^{*}=\left(\frac{\text { Lic }}{\text { Lic }_{0}}\right)^{\varepsilon_{\gamma}} \times \gamma_{0} \quad \text { Unit }: \frac{\text { Person }}{\text { Capital Unit }}
$$

where $\gamma_{0}$ is the labour requirement of capital at time $0, \frac{L i c}{L i c_{0}}$ is the relative increase of licences in use in comparison to time 0 , and $\varepsilon_{\gamma}$ is the Labour Requirement Elasticity on Licences in Use. This latter is assumed to have a value between -1 and 0 .

Fraction of tickets per job $\tau$ is calculated as:

$$
\tau=\left(\frac{\text { Lic }}{\text { Lic }_{0}}\right)^{\varepsilon_{\tau}} \times \tau_{0} \quad \text { Unit : } \frac{\text { Tickets }}{\text { Capital Unit }} \text { or } \frac{\text { Tickets }}{\text { Ticket }}
$$

where $\tau_{0}$ is the fraction of tickets per job at time $0, \frac{L i c}{L i c_{0}}$ is the relative increase of licences in use in comparison to time 0 , and $\varepsilon_{\tau}$ is the Fraction of Tickets per Job Elasticity on Licences in Use. This latter is assumed to have a value between -1 and 0 .

This structure pushes the system in a state of a constant disequilibrium driving change in every sector of the IN4.0-SD economy. As far as the exogenous curves defining new products entrants in the market are greater than those leaving the system, then the system will show growth of Licences in Use.

\section{Appendix A.2. Capacity Sub-Dimensions}

Figure A2 shows a combination of four sub-dimensions (Capital, Labour, Productivity of Capital and Labour Requirement per Unit of Capital) and shows the structure of the production function for both SOIB and DASB.

The desired production is the driver of the capacity management structure. If capacity builds up efficiently, each sector shall be able to supply enough services to keep customers satisfied and allow for stable business growth in the economy, as driven by both exogenous and endogenous dynamic disequilibrium factors.

While desired production $P^{*}$ is set as a driver for desired capital $K^{*}$, the capital structure drives the entire capacity management structure. This is calculated as:

$$
K^{*}=\frac{P^{*}}{\pi} \quad \text { Unit : Capital Unit }
$$

where $\pi$ is the productivity of capital and $P^{*}$ the desired production.

In a similar way capital drives labour such that desired labour $L^{*}$ (e.g., the amount of labour required for the desired level of capital) is calculated as:

$$
L^{*}=K^{*} \times \gamma \quad \text { Unit : People }
$$

where $K^{*}$ is the desired capital and $\gamma$ is the labour requirement per unit of capital, and indicated labour indL (e.g., the amount of labour required for the actual level of capital) is calculated as:

$$
\text { indL }=K \times \gamma \quad \text { Unit: People }
$$

A standard stock management structure and co-flows are used to assure that the properties of newly ordered capital are maintained into the capital vintage structure. It is worth noting that while the outflows from backlog are dependent either on the shipments from the SOIB and the cash availability of each sector, both capital addition and capital discard are calculated as a SMOOTH3 of the flow upstream to the capital vintage structure. Thus, both Capital Under Construction and the Capital stocks should be considered as third order vintage delays, as well as their co-flows determining Labour Requirement of Capital and Capital Productivity. 


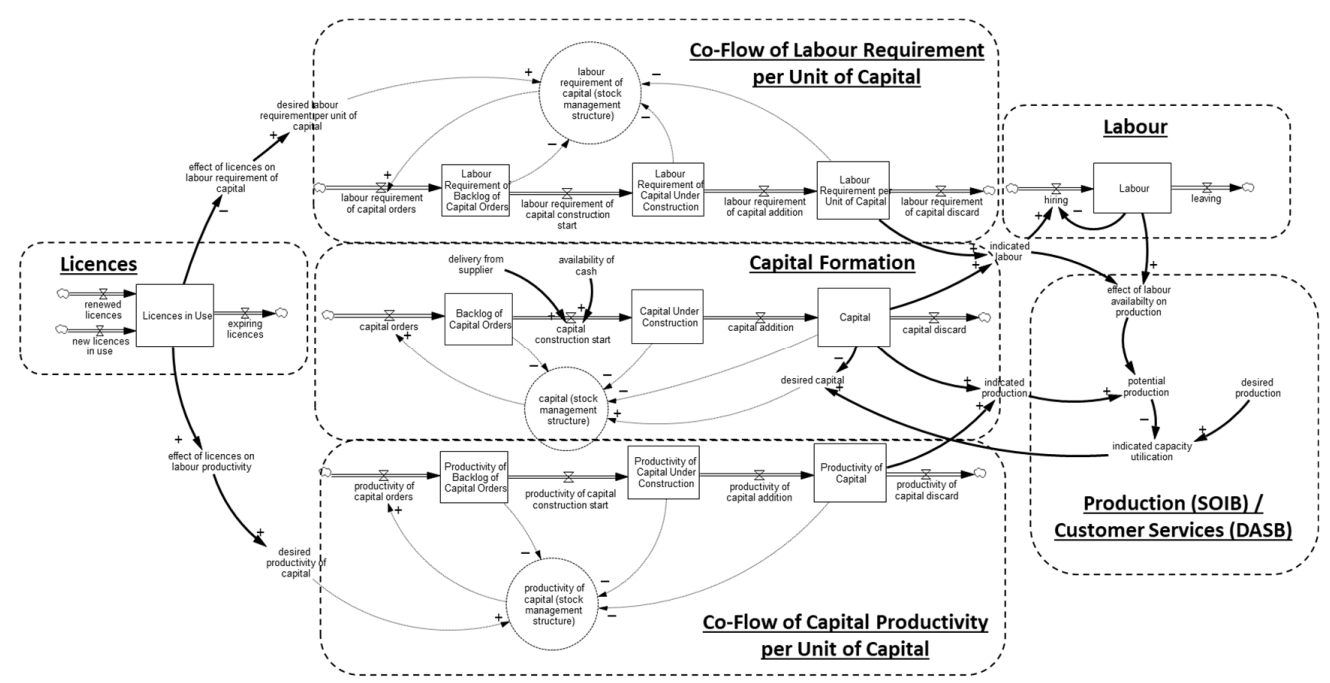

Figure A2. Capital, Labour Requirement of Capital, Capital Productivity, Labour and Output generation structures.

Based on these premises, the Indicated Production indP is calculated as:

$$
\text { indP }=K \times \pi \quad \text { Unit }: \frac{\text { Capital Units }}{\text { Month }} \text { or } \frac{\text { Tickets }}{\text { Month }}
$$

where $K$ is the stock of capital and $\pi$ is the productivity of that capital, and the resulting Production function is adjusted based on available labour as:

$$
P=\operatorname{IndP} \times \vartheta\left(\frac{L}{\text { indL }}\right) \quad \text { Unit }: \frac{\text { Capital Units }}{\text { Month }} \text { or } \frac{\text { Tickets }}{\text { Month }}
$$

where $\vartheta$ is a non-linear relationship determining the impact of labour availability on production as described in Figure A3, and $\frac{L}{i n d L}$ the labour availability ratio.

The resulting production function provides different insights from those available in the standard economic literature (e.g., Cobb-Douglas, Constant Elasticity of Substitution, or Leontief) as reviewed in Pasqualino and Jones [5]. This structure provides greater flexibility while at the same time assuming non-linear dynamics system assumptions and more realistic behaviour.

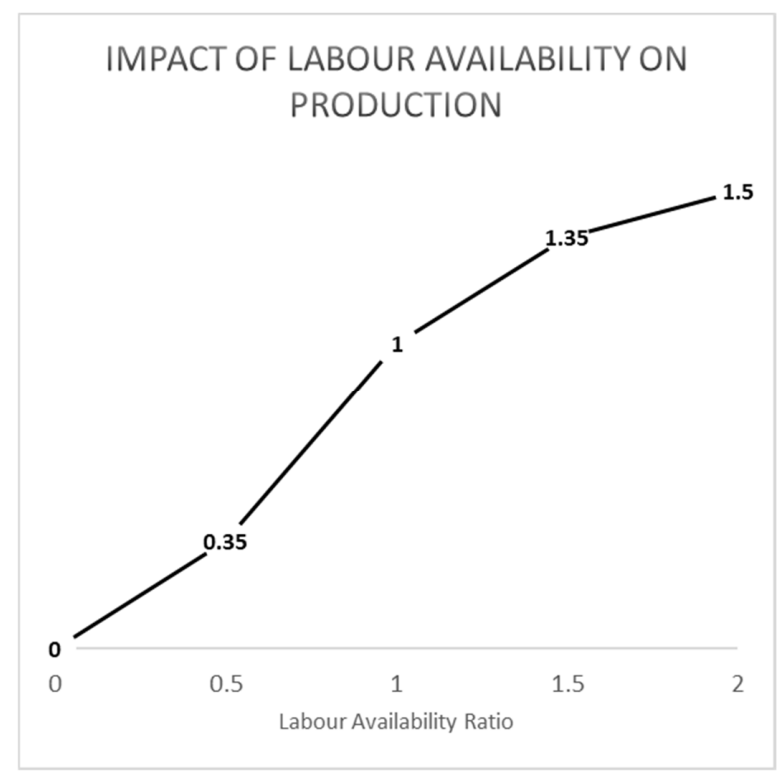

Figure A3. Non-linear relationship describing the impact of labour availability on production. 


\section{A Note on Most Common Production Functions}

The three most used forms of production function are:

- Cobb-Douglas Production function

- Constant Elasticity of Substitution Production function

- Leontief Input-Output Production function

The Cobb-Douglas (CB) is an equation which takes the following form:

$$
P=P_{0}\left(\frac{K}{K_{0}}\right)^{\varepsilon}\left(\frac{L}{L_{0}}\right)^{1-\varepsilon}
$$

where $P$ is production, $K$ is the Capital, $K_{0}$ is the capital at the beginning of the simulation, $L$ is the labour, $L_{0}$ is the labour at the beginning of the simulation, $\varepsilon$ is a parameter between 0 and 1 representing the elasticity of substitution between labour and capital to obtain production. One of the major reasons why this formulation often used in economics is that it is continuous for every value of $K$, and $L$, thus allowing for the calculation of the marginal productivity of every input factor by calculating the derivative of $P$ based on every productive factor. This property allows for the calculation of the investments by assuming on rational expectations and perfect foresights of decision makers to reach desired levels of output. Under the assumption of increases in demand, the formulation would result in constant growth of labour and capital.

A weakness of the CB for the purpose of the IN4.0 is that when testing the possible implication of shortages of one or the other productive factor, the constant elasticity would make the other factor to automatically adjust, assuring the perfect substitutability of one factor for the other. In addition, Shahik (1970) [52] argued that such a formulation should not even be called a production function, simply because its properties would allow the equation to match to whatever pattern of historical data, making it unsuitable for the purpose it is supposed to fulfil.

The CES production function is a more sophisticated formulation that builds up on the $\mathrm{CB}$, and it takes the following form:

$$
P=P_{0}\left(\varepsilon{\frac{K}{K_{0}}}+(1-\varepsilon){\frac{L}{L_{0}}}^{-\rho}\right)^{-\frac{1}{\rho}}
$$

where $\varepsilon$ represents the value share of capital, $(1-\varepsilon)$ represents the value share of labour on total production, and the $\rho$ the elasticity of substitution between capital and labour. The equation does not solve for $\rho=0$, however, it is possible to demonstrate that calculating the limit of the equation with $\rho$ tending to zero, the result would be exactly the CB. Test 3 of Appendix 2 of Pasqualino and Jones (2020) [51] demonstrates how the the CES production function does not apply well when the factors of productivity change in composition to generate production. While testing the reduction in energy consumption per unit of capital, the test demonstrated how the CES generates balancing effect that allow, for example, to increase the amount of capital required to generate production, despite energy is simply embedded in capital and should rather determine an improvement in technology rather than a change in capital demand and productivity.

The IN4.0-SD ad-hoc production function solves this problem by using one factor as driven by the demand, and the other that depends on the first factor, and providing enough flexibility to change capital properties such as productivity, and labour requirement per unit of capital without altering the effects via unwanted unbalancing feedback effects.

On the other hand, the Leontief production function can be described by the following equation:

$$
P=\min \left(P_{K}, P_{L}\right)=\min \left(K \cdot \pi_{K}, L \cdot \pi_{L}\right)
$$

where $P$ is production, $P_{K}$ is the maximum production reachable from Capital, $P_{L}$ the maximum production with available labour, $K$ is capital, $L$ is Labour, $\pi_{K}$ is the productivity of one unit of capital and $\pi_{L}$ is the productivity of every worker. The standard formulation 
of the Leontief production function assumes no substitutability between the two production factors, thus providing less flexibility than Cobb-Douglas in allowing the equation to match historical data. However, the Leontief does not apply well to the purpose of the IN4.0-SD, which is ultimately a top-level perspective system model which solves in continuous time and supporting the view of a policy maker or high level decision maker in a firm. On the other hand the Leontief production function would be more suitable for low scale dynamic systems, such the decision making of a single firm managing cash, with the production factor to generate supply.

\section{Appendix A.3. Production and Customer Services}

Figure A4 shows the production backlog and how new orders are generated in each model. The capital orders in SOIB (right hand side of Figure A4) are calculated as the sum of the capital orders from every sector. The orders accumulate in the backlog and decreases due to shipments. The desired production structure accounts for both the estimation of future orders, and adjustment from backlog and inventory based on future requirement. Estimation is based on the TRND function, mimicking the behaviour of firm to adopt econometric method, based on imperfect data, and remaining biased by past performance rather than future estimates [43].

The ratio between desired and potential production determines the Indicated Capacity Utilization that is corrected with a capacity utilization table function according to the shape of Figure A5. Based on this curve, if demand decreases below supply, the behaviour is to remove a little more backlog than required thus keeping labour busy and exploiting their time during periods of low demand. When demand is above capacity, it is assumed that workers can increase their capacity to accommodate demand but not so flexibly due to friction in human endurance.

In IN4.0-SD it is assumed that when production is scheduled (both for SOIB and DASB) there is a number of jobs which require opening tickets that form the demand for the customer service of DASB. These can be seen from requests to produce better products to solving bugs in their digital products. Thus, DASB opens new tickets, and plans capacity to be able to solve them.

This brings to the tickets processing capacity management, leading back to requirements of new capital, and licences to meet those requirements. In a similar way to SOIB, DASB schedules capital and labour to start solving tickets. Being DASB also relying on licences to solve tickets, it also ends up opening further tickets that must be accounted for production. It is assumed that tickets take an average time to be closed, and delivered, thus reducing backlog, and supporting their clients with efficient production. If, for whatever reason, the DASB cannot solve them, the service reduction is reflected in lower capacity of SOIB to deliver their production to inventory and increases the delay time of DASB to solve those tickets. This is a self-reinforcing loop that can generate instability in IN4.0-SD.

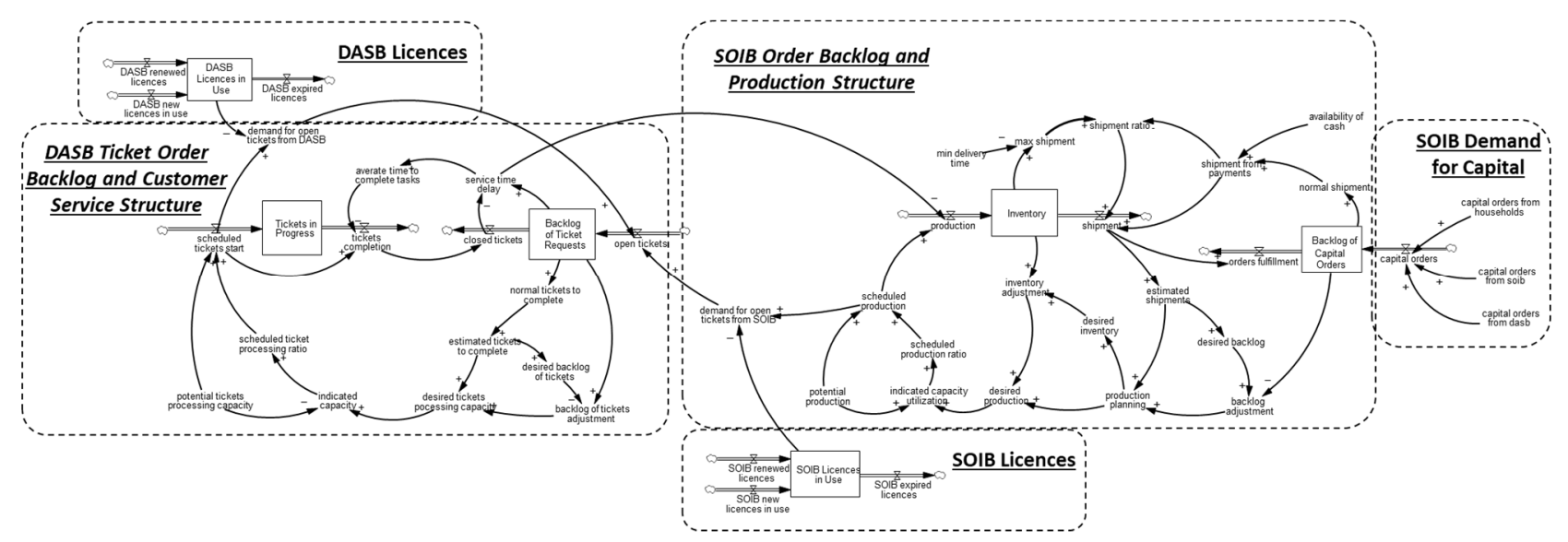

Figure A4. Production and Customer Services. 


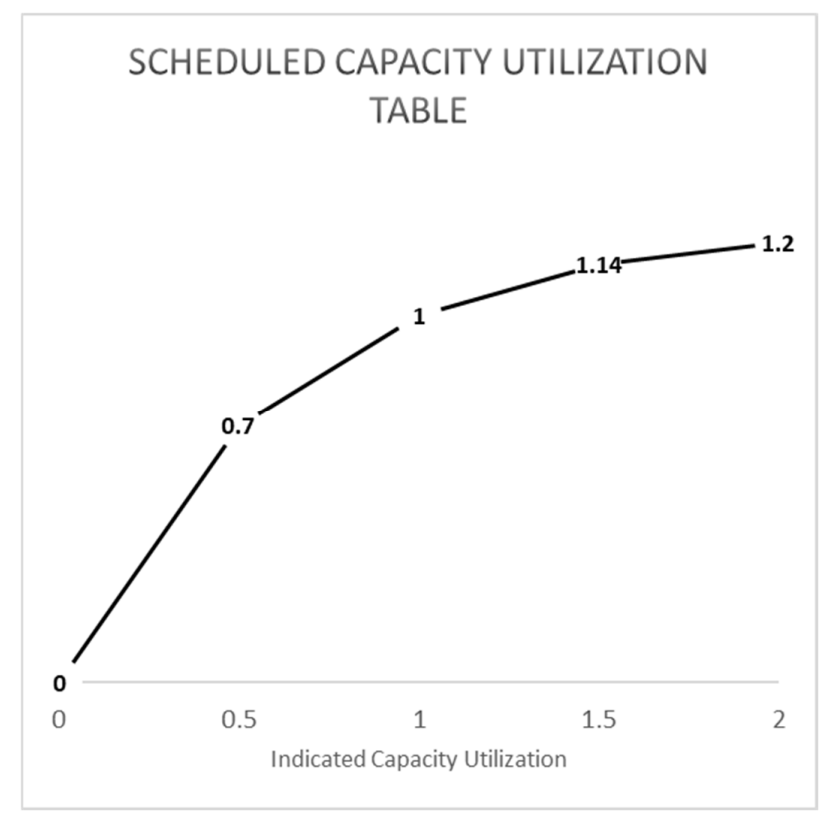

Figure A5. Scheduled capacity utilization table function.

Appendix A.4. Prices and Wages

IN4.0-SD endogenously models wages and prices using system of pressures based on past performance (see Figure A6). The pressures for wage change are generated from both (i) labour demand to availability ratio, and (ii) growth in labour productivity (the output generated by every worker). If labour demand is beyond the labour that is currently employed, then wages will tend to decrease. In the opposite case they would rise. On the other hand, if workers productivity increases, this can lead to pressures increasing wage over time. This can be generated both by reducing labour requirement of capital by maintaining constant productivity, and by rising capital productivity with the same amount of labour.

Prices are assumed being not impacted by costs (e.g., wages do not feedback to price). Rather these are assumed to being driven by market forces alone. On the side of SOIB, it is assumed that when desired inventory (the inventory required to assure desired supply) is higher than actual inventory, this will generate inflationary pressures to increase price. With regards to DASB, it is assumed that the price increases are inversely proportional to the growth rate of the market, assumed as a key driver for determining customer interest and service supply.
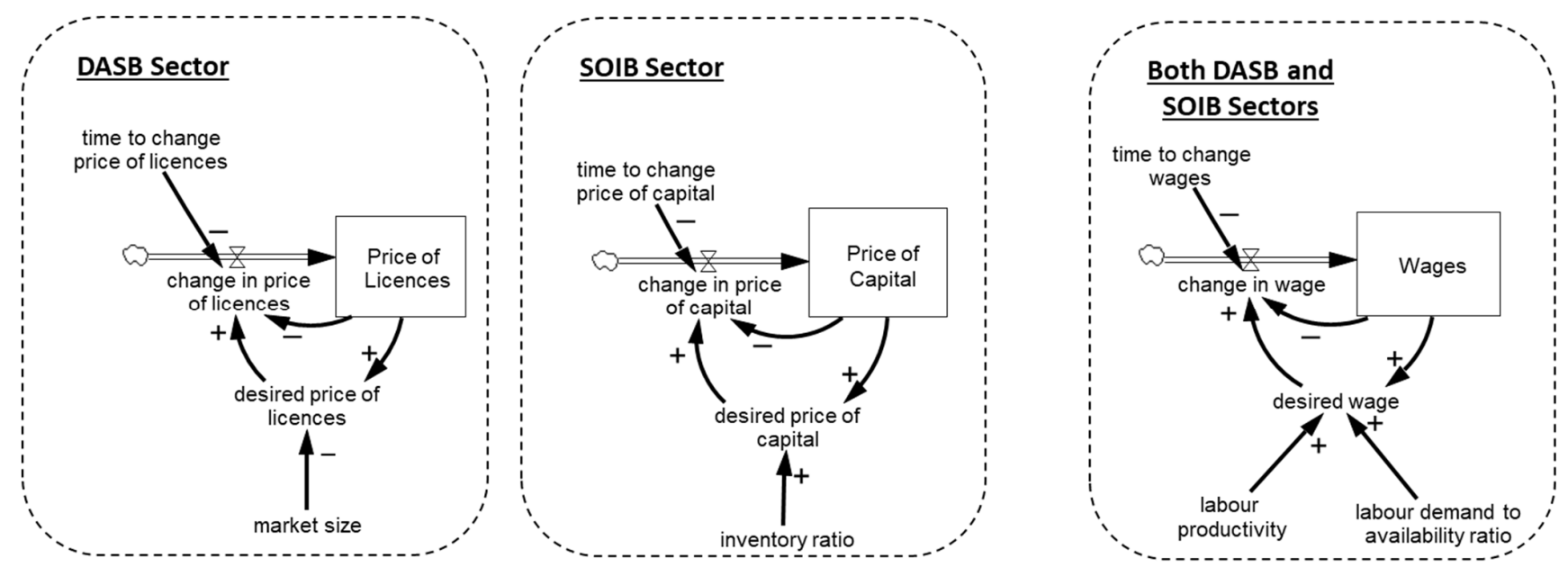

Figure A6. Prices and Wages. 


\section{Appendix A.5. Cash and Financial Decisions}

Closing the feedback loops from real to financial and back to real dimensions, Figure A7 shows the modelling of cash availability and their impact on decision making. The desired cash expenditures are determined by the indicated levels of purchases of licences, the indicated level of purchases for new capital, and the desired payments to labour. These are compared to the max spending with available cash. If actual cash is lower than what sufficient to assure payments are fulfilled, then these will be gradually contained with subsequent effect on reducing system capacity and generating instability. This is important to assure financial stock and flow consistency of every sector in the economy.

As a simplifying assumption, if cash is not sufficient to make payment, borrowing is assumed to be generated at no cost, thus representing all money supply in the system. If businesses perform well, and profits are larger than costs, than money surpluses are distributed as dividends. The dynamics interplay of dividends compared to wage and labour payments forms the basis for the study of inequality as proposed in this paper.

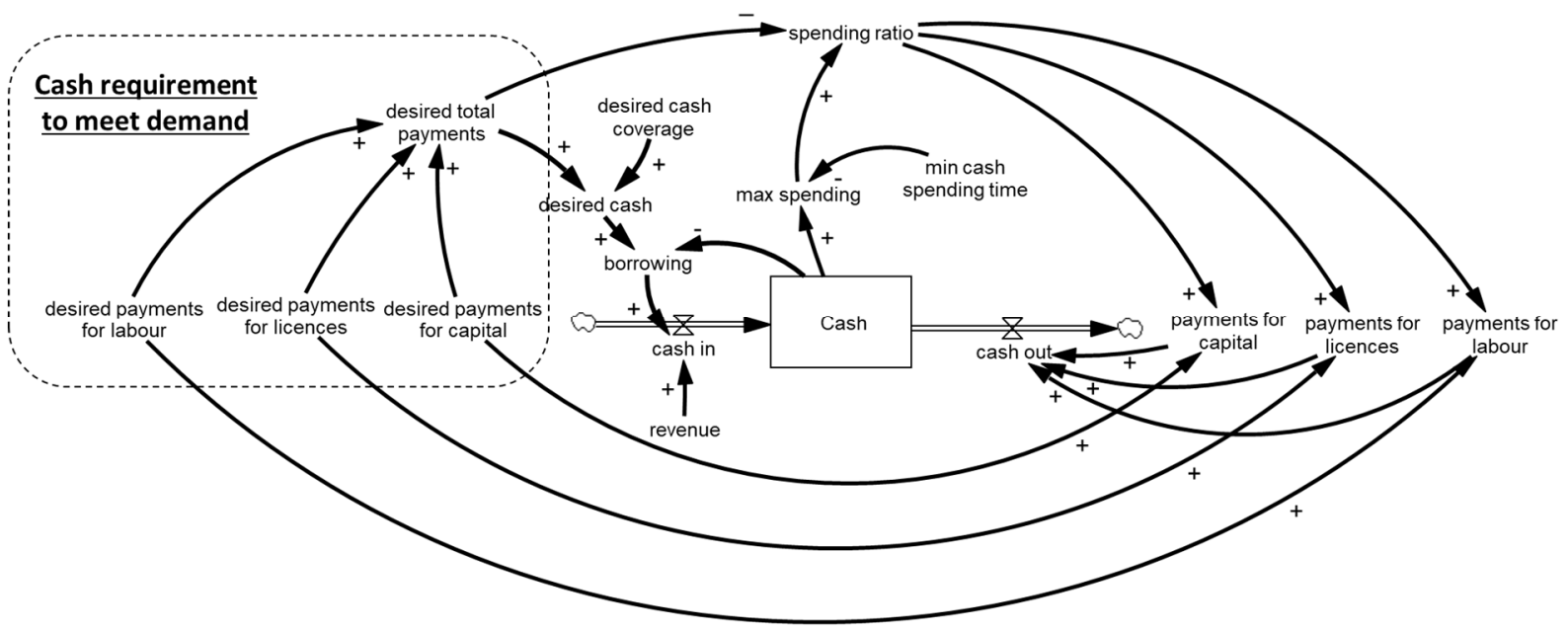

Figure A7. Cash and financial decisions.

\section{Appendix B. Univariate Sensitivity Analyses of DAS and SOI Entities}

Appendix B is supplementary to Section 4.4 of the paper by describing two univariate sensitivity experiments to demonstrate the impact of the chosen sensitivity parameters from both sectors on a set of output variables. The paper considers a two-factorial set of 256 experiments based on the sensitivity of eight parameters, which can be mirrored between two groups of four parameters that have the same role for influencing both SOIB and DASB sectors. This analysis applies a univariate sensitivity analysis for each of the two group of four parameters, dividing them by sector.

\section{Appendix B.1. Univariate Analysis for DASB}

Table A1 shows the parameters used for the DASB entity, both low and high levels of sensitivity, the steps between one simulation and another for every parameter, and the resulting simulations per each parameter. Differently from the two-factorial type of analysis, the univariate considers every variation in parameters without varying other parameters. The result is the sum of simulations taken one by one. In this case it is $5+6+6+6=23$ simulations.

Figure A8 shows the result of varying the elasticities of the DASB entity while keeping everything else equal. This shows well how the licences in use impact on the (i) capital productivity, (ii) labour requirement per unit of capital and (iii) fraction of open tickets per job. Without considering any change in SOIB parameters, the same variables appear unvaried for the simulation. 
Table A1. Parameters' choice and range for DASB univariate sensitivity analysis.

\begin{tabular}{ccccc}
\hline Parameter & Low Level & High Level & Step & Total Levels \\
\hline Price Elasticity on Market Size & -0.2 & 0 & 0.05 & 5 \\
Open Tickets per Job Elasticity on Licences in Use & -0.5 & 0 & 0.1 & 6 \\
Labour Requirement Elasticity on Licences in Use & -0.5 & 0 & 0.1 & 6 \\
Capital Productivity Elasticity on Licences in Use & 0 & 0.5 & 0.1 & 6 \\
\hline
\end{tabular}

Figure A9 shows how the sensitivity of DASB impacts on SOIB in the model. It is worth noting how the model is set to behave given the chosen parameters, in particular assuming growth in capital productivity and reduction in labour requirement per unit of capital and open tickets per job. The most relevant factor in this Figure is the low impact of large variations in the DASB business in impacting the SOIB.

Figure A10 shows how the sensitivity impact on the overall economy of the IN4.0SD model. It is worth noting how no specific change in behaviour is considered in this simulation, while influencing significantly on the Average Price on Average Wage ratio, that is mostly due to the large variations on labour demand and wage impact for the DASB sector.
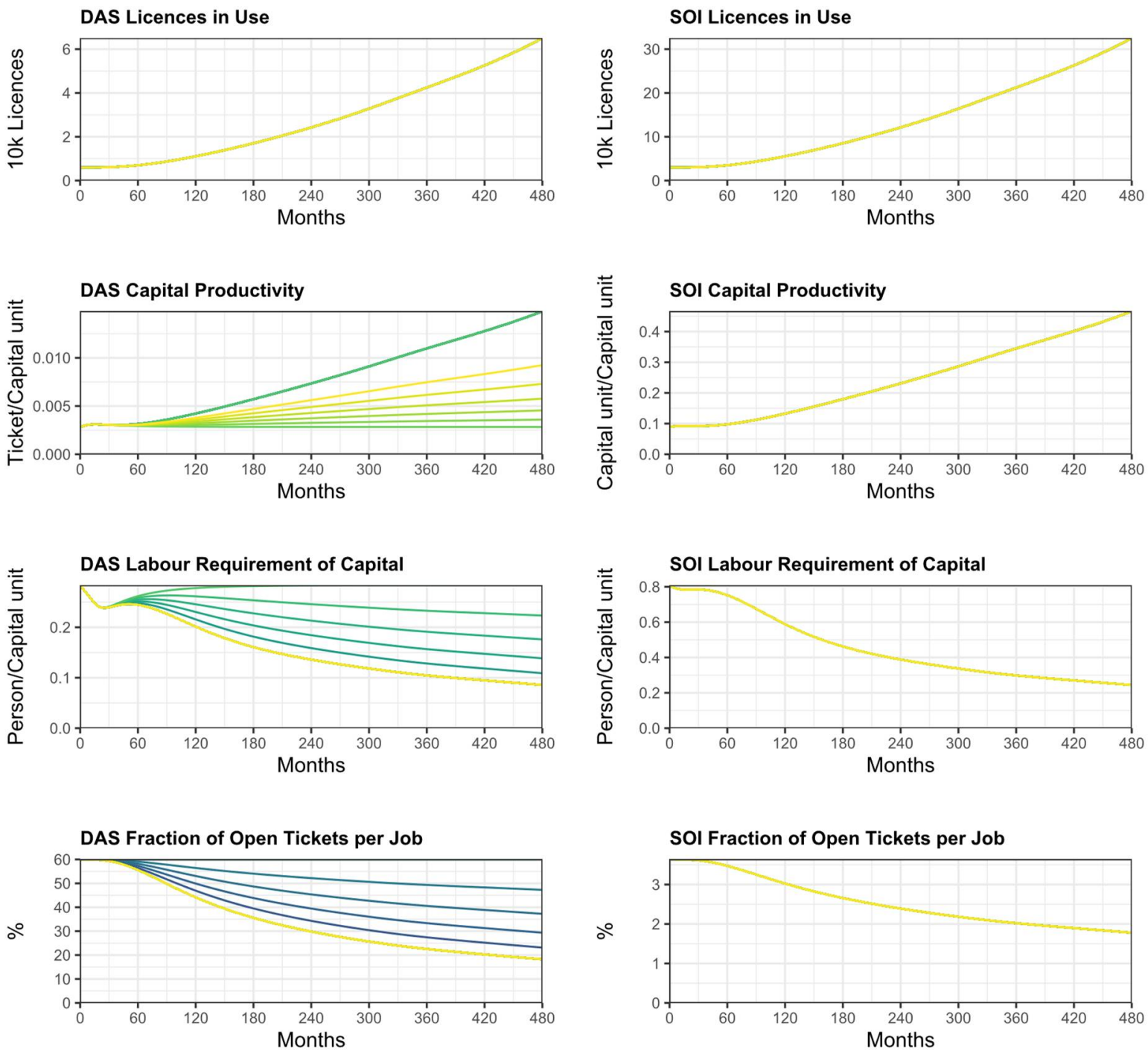

Figure A8. Input parameters for sensitivity of DAS. 

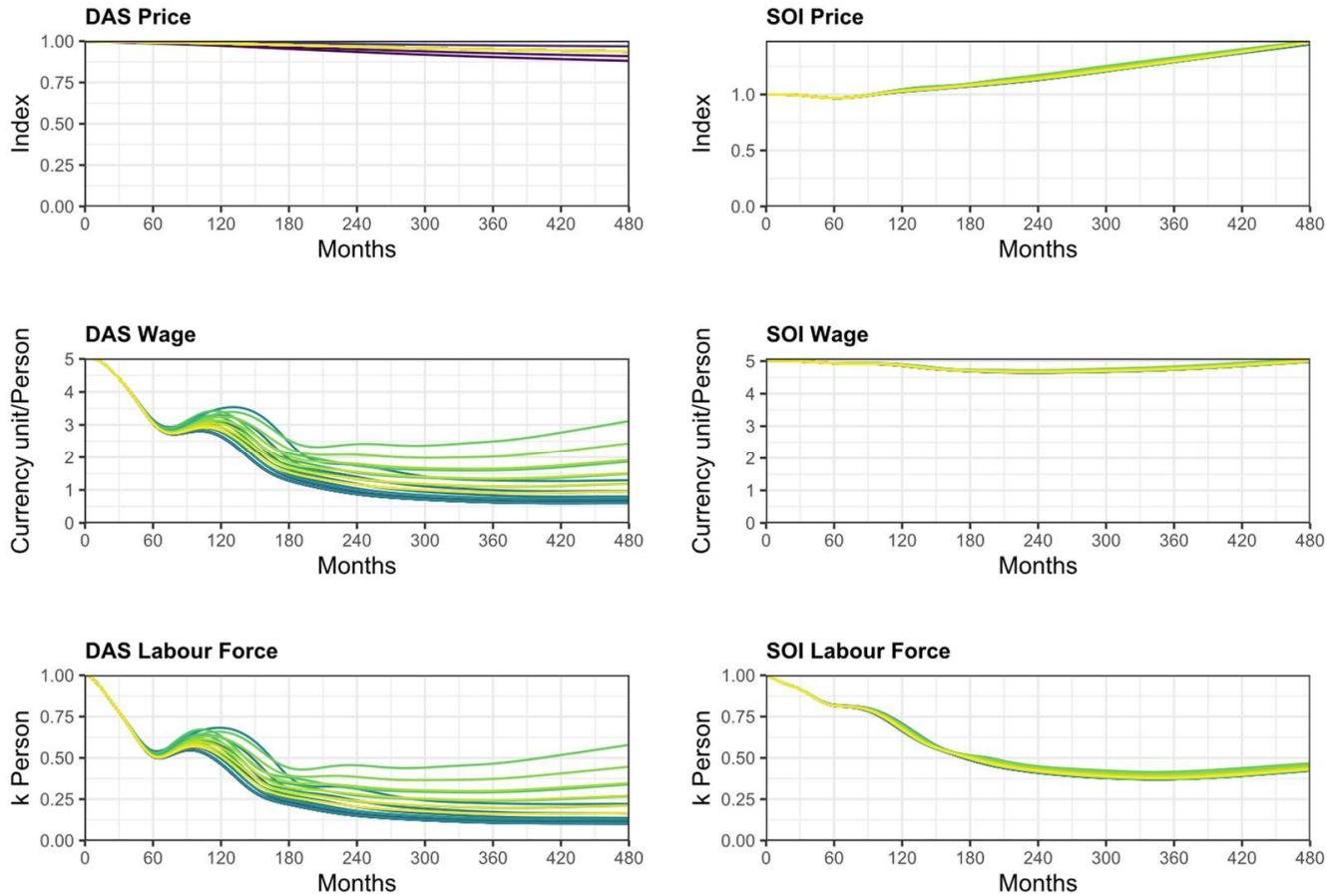

Figure A9. Impact of DAS univariate sensitivity on SOI.
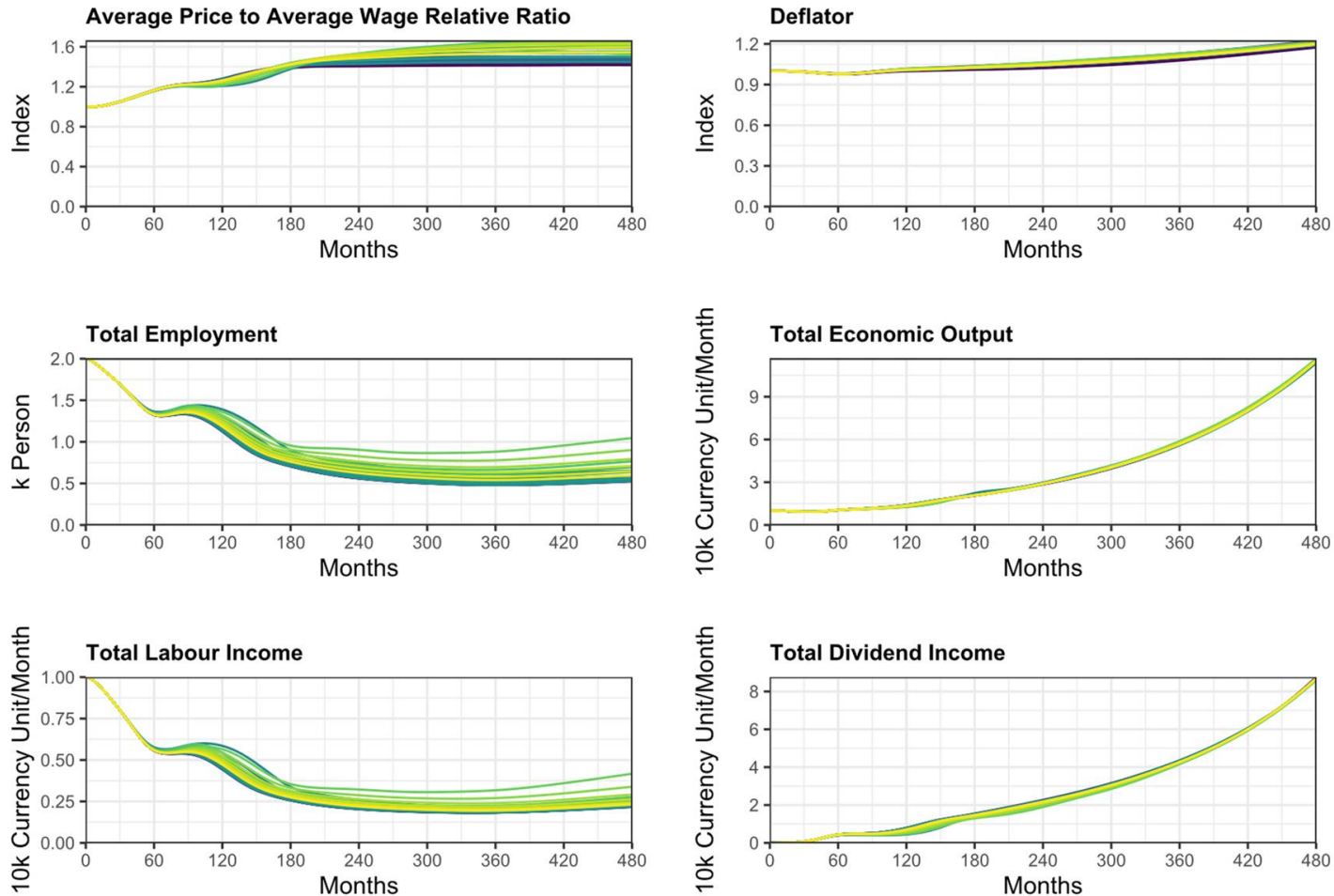

Figure A10. Impact of DAS Sensitivity on overall economy.

Appendix B.2. Univariate Analysis for SOIB

Table A2 shows the parameters used for the SOIB entity, both low and high levels of sensitivity, the steps between one simulation and another for every parameter, and the resulting simulations per each parameter. Similarly to the previous case of univariate sensitivity on DASB entity, the total number of simulations is 23 . 
Table A2. Parameters' choice and range for SOIB univariate sensitivity analysis.

\begin{tabular}{ccccc}
\hline Parameter & Low Level & High Level & Step & Total Levels \\
\hline Price Elasticity on Inventory Gap & 0 & 0.2 & 0.05 & 5 \\
Open Tickets per Job Elasticity on Licences in Use & -0.5 & 0 & 0.1 & 6 \\
Open Tickets per Job Elasticity on Licences in Use & -0.5 & 0 & 0.1 & 6 \\
Open Tickets per Job Elasticity on Licences in Use & 0 & 0.5 & 0.1 & 6 \\
\hline
\end{tabular}

Figure A11 shows the result of varying the elasticities of the SOIB entity while keeping everything else equal. This provides results that mirror the one of the sensitivity for DASB. While the change in the variables (i) capital productivity, (ii) labour requirement per unit of capital and (iii) fraction of open tickets per job is very visible, no change is considered for the DASB.

Figure A12 shows how the sensitivity of SOIB impacts on DASB in the model. It is worth noting that SOIB must respond to the demand from Households which is exogenously set and assumed to grow exponentially and being unaffected by any endogenous influence emerging from the model. The result is a rising employment in SOIB in comparison to what can be seen in DASB, with corresponding higher wages and prices.

Figure A13 shows how the overall impact on the economy, demonstrating how SOIB influence the wider economy more than how DASB does, including higher impact on deflator, labour employment and labour payment. Despite of it, dividend rate remains higher than labour payment resulting in high inequality emerging from these set of scenarios as well.
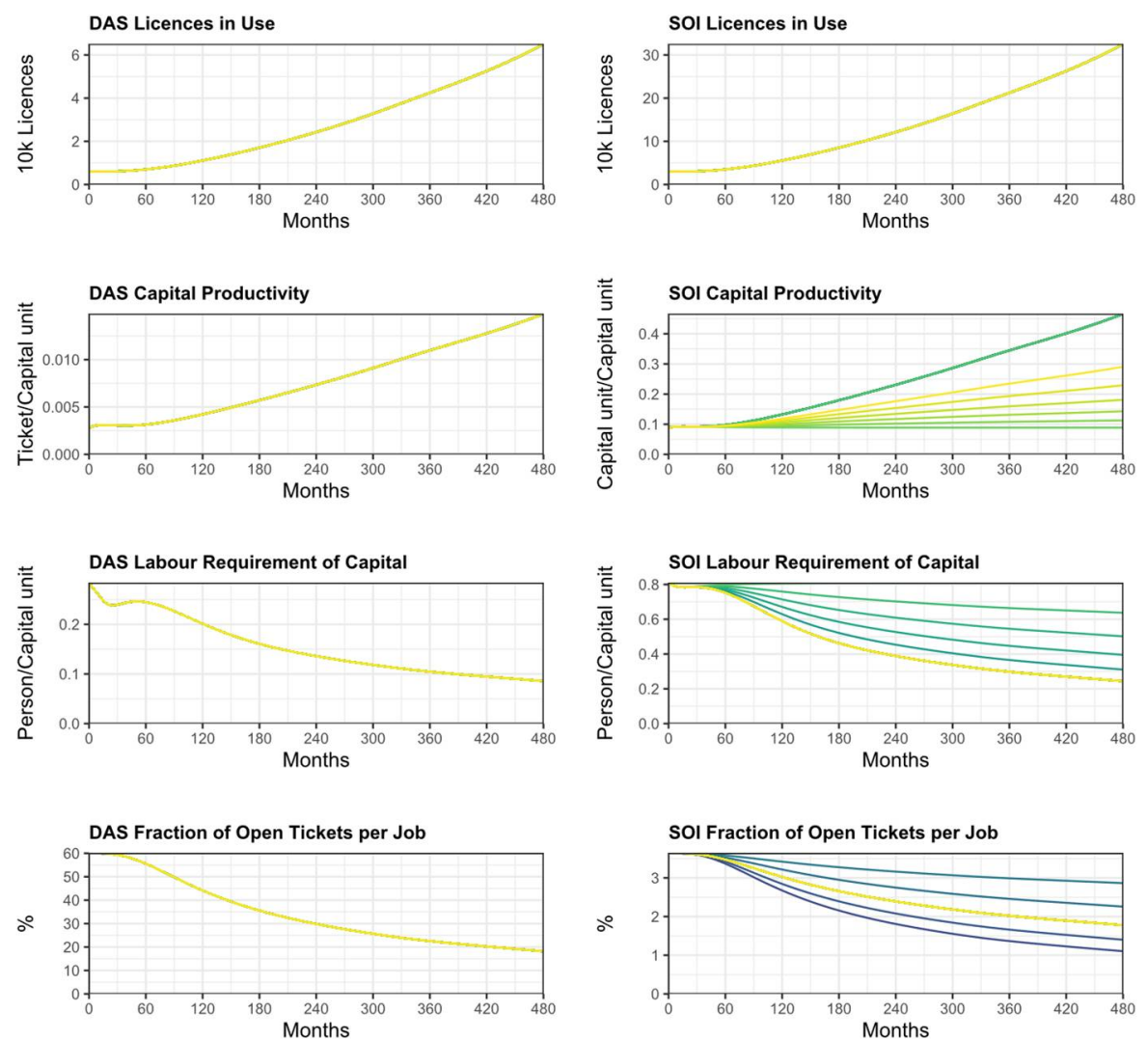

Figure A11. Input parameters for sensitivity of SOI on DAS. 

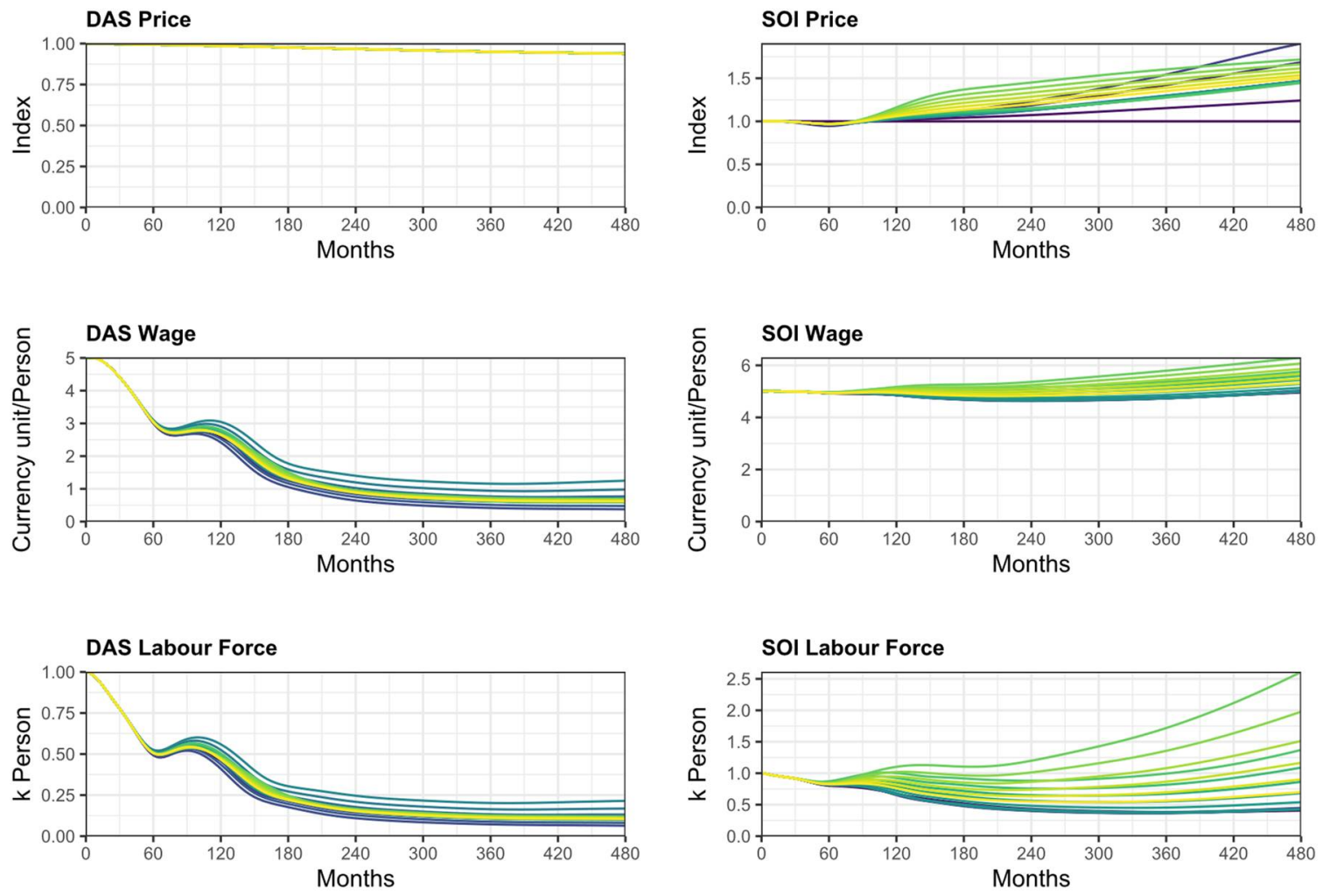

Figure A12. Impact of SOI Sensitivity on DAS.
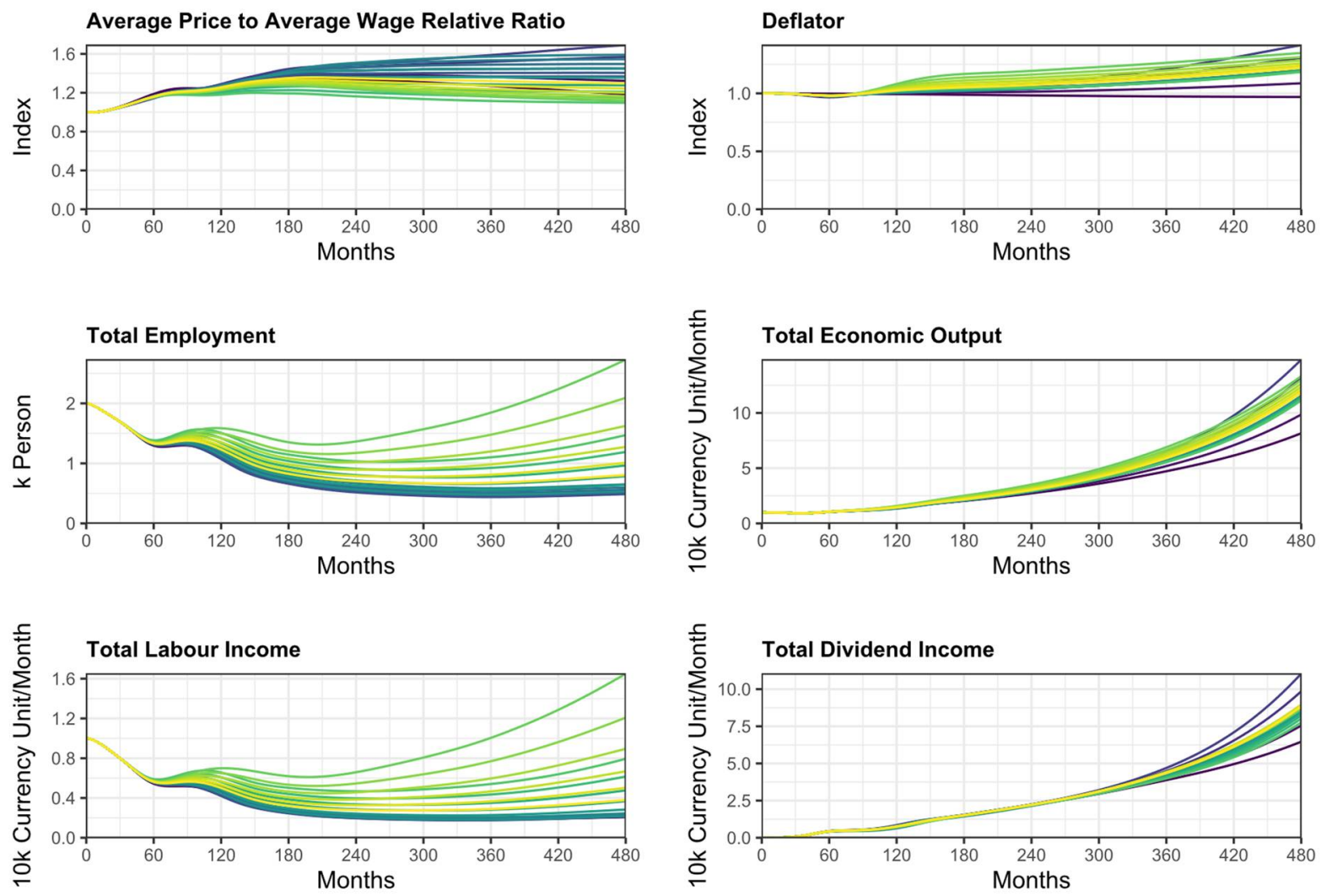

Figure A13. Impact of SOI Sensitivity on overall economy. 


\section{References}

1. Demartini, M.; Taticchi, P. How Environmental and Social Issues Affect Business Strategy. In Corporate Sustainability in Practice. Management for Professionals; Taticchi, P., Demartini, M., Eds.; Springer: Cham, Switzerland, 2021. [CrossRef]

2. Naseem, M.H.; Yang, J. Role of Industry 4.0 in Supply Chains Sustainability: A Systematic Literature Review. Sustainability 2021, 13, 9544. [CrossRef]

3. Van der Waal, J.W.; Thijssens, T.; Maas, K. The innovative contribution of multinational enterprises to the Sustainable Development Goals. J. Clean. Prod. 2021, 285, 125319. [CrossRef]

4. Maxton, G.; Randers, J. Reinventing Prosperity: Managing Economic Growth to Reduce Unemployment, Inequality, and Climate Change; Greystone Books: Vancouver, BC, Canada, 2016.

5. Pasqualino, R.; Jones, A.W. Resources, Financial Risk and the Dynamics of Growth: Systems and Global Society; Routledge: Oxford, UK, 2020.

6. Zhai, P.; Pörtner, H.O.; Roberts, D.; Skea, J.; Shukla, P.R.; Pirani, A.; Moufouma-Okia, W.; Péan, C.; Pidcock, R. Global warming of $1.5^{\circ} \mathrm{C}$. In An IPCC Special Report on the Impacts of Global Warming of $1.5^{\circ} \mathrm{C}$ above Pre-Industrial Levels and Related Global Greenhouse Gas Emission Pathways, in the Context of Strengthening the Global Response to the Threat of Climate Change, Sustainable Development, and Efforts to Eradicate Poverty; World Meteorological Organization: Geneva, Switzerland, 2018; p. 32.

7. Meadows, D.; Randers, J.; Meadows, D. The Limits to Growth: The 30-Year Update; Chelsea Green Publishing Company: Chelsea, VT, USA, 2004.

8. Meadows, D.H.; Randers, J.; Meadows, D.L. The Limits to Growth; Yale University Press: New Haven, CT, USA, 1972.

9. Luisi, P.L. The Emergence of Life: From Chemical Origins to Synthetic Biology; Cambridge University Press: Cambridge, UK, 2016.

10. Maletič, M.; Maletič, D.; Dahlgaard, J.J.; Dahlgaard-Park, S.M.; Gomišček, B. Effect of sustainability-oriented innovation practices on the overall organisational performance: An empirical examination. Total Qual. Manag. Bus. Excell. 2016, 27, 1171-1190. [CrossRef]

11. Schneider, P. Managerial challenges of Industry 4.0: An empirically backed research agenda for a nascent field. Rev. Manag. Sci. 2018, 12, 803-848. [CrossRef]

12. Deslatte, A.; Feiock, R.C.; Wassel, K. Urban pressures and innovations: Sustainability commitment in the face of fragmentation and inequality. Rev. Policy Res. 2017, 34, 700-724. [CrossRef]

13. Geradts, T.H.; Bocken, N.M. Driving sustainability-oriented innovation. MIT Sloan Manag. Rev. 2019, 60, 1.

14. Adams, R.; Jeanrenaud, S.; Bessant, J.; Denyer, D.; Overy, P. Sustainability-oriented innovation: A systematic review. Int. J. Manag. Rev. 2016, 18, 180-205. [CrossRef]

15. Voegtlin, C.; Scherer, A.G. Responsible innovation and the innovation of responsibility: Governing sustainable development in a globalized world. J. Bus. Ethics 2017, 143, 227-243. [CrossRef]

16. Tanaka, N.; Glaude, M.; Gault, F. OECD/Eurostat. Oslo Manual: Guidelines for Collecting and Interpreting Innovation Data, 3rd ed.; The Measurement of Scientific and Technological Activities; OECD Publishing: Paris, France, 2005. [CrossRef]

17. Noci, G.; Verganti, R. Managing 'green'product innovation in small firms. RD Manag. 1999, 29, 3-15.

18. Bianchi, R.; Noci, G. “Greening” SMEs' Competitiveness. Small Bus. Econ. 1998, 11, 269-281. [CrossRef]

19. Hoffrén, J.; Apajalahti, E.L. Emergent eco-efficiency paradigm in corporate environment management. Sustain. Dev. 2009, 17, 233-243. [CrossRef]

20. Roome, N. Looking back, thinking forward: Distinguishing between weak and strong sustainability. In The Oxford Handbook of Business and the Natural Environment; Oxford University: Oxford, UK, 2012.

21. Klewitz, J.; Hansen, E.G. Sustainability-oriented innovation of SMEs: A systematic review. J. Clean. Prod. 2014, 65, 57-75. [CrossRef]

22. Inigo, E.A.; Ritala, P.; Albareda, L. Networking for Sustainability: Alliance Capabilities and Sustainability-Oriented Innovation. Industrial Marketing Management; Elsevier: Amsterdam, The Netherland, 2020; pp. 550-565.

23. Schilke, O.; Goerzen, A. Alliance management capability: An investigation of the construct and its measurement. J. Manag. 2010, 36, 1192-1219. [CrossRef]

24. Leischnig, A.; Geigenmüller, A. When does alliance proactiveness matter to market performance? A comparative case analysis. Ind. Mark. Manag. 2018, 74, 79-88. [CrossRef]

25. Goodman, J.; Korsunova, A.; Halme, M. Our collaborative future: Activities and roles of stakeholders in sustainability-oriented innovation. Bus. Strategy Environ. 2017, 26, 731-753. [CrossRef]

26. Inigo, E.A.; Albareda, L. Sustainability oriented innovation dynamics: Levels of dynamic capabilities and their path-dependent and self-reinforcing logics. Technol. For. Soc. Chang. 2019, 139, 334-351. [CrossRef]

27. Du Plessis, M. The role of knowledge management in innovation. J. Knowl. Manag. 2007, 11, 20-29. [CrossRef]

28. López-Nicolás, C.; Meroño-Cerdán, Á.L. Strategic knowledge management, innovation and performance. Int. J. Inf. Manag. 2011, 31, 502-509. [CrossRef]

29. Tura, N.; Ojanen, V.; Hanski, J. Innovations for sustainability: Challenges of utilising sustainability-related knowledge. Int. J. Innov. Sustain. Dev. 2019, 13, 452-478. [CrossRef]

30. Bos-Brouwers, H.E.J. Corporate sustainability and innovation in SMEs: Evidence of themes and activities in practice. Bus. Strategy Environ. 2010, 19, 417-435. [CrossRef] 
31. Moore, S.B.; Manring, S.L. Strategy development in small and medium sized enterprises for sustainability and increased value creation. J. Clean. Prod. 2009, 17, 276-282. [CrossRef]

32. Wu, G.C. Effects of socially responsible supplier development and sustainability-oriented innovation on sustainable development: Empirical evidence from SMEs. Corp. Soc. Responsib. Environ. Manag. 2017, 24, 661-675. [CrossRef]

33. Van de Wetering, R.; Mikalef, P.; Helms, R. Driving organizational sustainability-oriented innovation capabilities: A complex adaptive systems perspective. Curr. Opin. Environ. Sustain. 2017, 28, 71-79. [CrossRef]

34. Mead, T.; Jeanrenaud, S.; Bessant, J. Factors influencing the application of nature as inspiration for sustainability-oriented innovation in multinational corporations. Bus. Strategy Environ. 2020, 29, 3162-3173. [CrossRef]

35. Bustamante, M.J. Using Sustainability-Oriented Process Innovation To Shape Product Markets. Int. J. Innov. Manag. 2020, 24, 2040001. [CrossRef]

36. Raworth, K. Doughnut Economics: Seven Ways to Think Like a 21st-Century Economist; Chelsea Green Publishing: Chelsea, VT, USA, 2017.

37. Hekkert, M.P.; Suurs, R.A.; Negro, S.O.; Kuhlmann, S.; Smits, R.E. Functions of innovation systems: A new approach for analysing technological change. Technol. Forecast. Soc. Chang. 2007, 74, 413-432. [CrossRef]

38. Kazancoglu, Y.; Ekinci, E.; Mangla, S.K.; Sezer, M.D.; Kayikci, Y. Performance evaluation of reverse logistics in food supply chains in a circular economy using system dynamics. Bus. Strategy Environ. 2021, 30, 71-91. [CrossRef]

39. Li, Y.; Dai, J.; Cui, L. The impact of digital technologies on economic and environmental performance in the context of industry 4.0: A moderated mediation model. Int. J. Prod. Econ. 2020, 229, 107777. [CrossRef]

40. Lobova, S.V.; Alekseev, A.N.; Litvinova, T.N.; Sadovnikova, N.A. Labor division and advantages and limits of participation in creation of intangible assets in industry 4.0: Humans versus machines. J. Intellect. Cap. 2020, 21, 623-638. [CrossRef]

41. Dosi, G.; Piva, M.; Virgillito, M.E.; Vivarelli, M. Embodied and disembodied technological change: The sectoral patterns of job-creation and job-destruction. Res. Policy 2021, 50, 104199. [CrossRef]

42. Prause, M.; Günther, C. Technology diffusion of Industry 4.0: An agent-based approach. Int. J. Comput. Econ. Econom. 2019, 9, 29-48. [CrossRef]

43. Sterman, J. Business Dynamics; McGraw-Hill: New York, NY, USA, 2000.

44. Bass, F.M. A new product growth for model consumer durables. Manag. Sci. 1969, 15, 215-227. [CrossRef]

45. Forrester, J. Industrial Dynamics; Currently Available from Pegasus Communications; MIT Press: Waltham, MA, USA, 1961.

46. Tversky, A.; Kahneman, D. Judgment under uncertainty: Heuristics and biases. Science 1974, 185, 1124-1131. [CrossRef] [PubMed]

47. Sterman, J.D. Systems simulation. Expectation formation in behavioral simulation models. Behav. Sci. 1987, 32, 190-211. [CrossRef]

48. Montgomery, D.C. Design and Analysis of Experiments; John Wiley \& Sons: Hoboken, NJ, USA, 2017.

49. Arthur, W.B. Foundations of complexity economics. Nat. Rev. Phys. 2021, 3, 136-145. [CrossRef]

50. Lavoie, M. Post-Keynesian Economics: New Foundations; Edward Elgar Publishing: Cheltenham, UK, 2014.

51. Pasqualino, R.A.J.A. Appendix of Resources, Financial Risk and the Dynamics of Growth: Systems and Global Society. 2020. Available online: https:/ / aru.figshare.com/articles/code/Economic_Risk_Resources_and_Environment_ERRE_model/10110710. (accessed on 6 October 2021).

52. Shaikh, A. Laws of production and laws of algebra: The humbug production function. Rev. Econ. Stat. 1974, 115-120. [CrossRef]

53. Carvalho, L.; Di Guilmi, C. Technological unemployment and income inequality: A stock-flow consistent agent-based approach. J. Evol. Econ. 2020, 30, 39-73. [CrossRef]

54. Sterman, J. The Energy Transition and the Economy: A System Dynamics Approach; MIT Alfred P. Sloan School of Management: Cambridge, MA, USA, 1981.

55. Forrester, J.W. Dynamic models of economic systems and industrial organizations. Syst. Dyn. Rev. J. Syst. Dyn. Soc. 2003, 19, 329-345. [CrossRef]

56. Lu, Y.; Wang, F. From general discrimination to segmented inequality: Migration and inequality in urban China. Soc. Sci. Res. 2013, 42, 1443-1456. [CrossRef]

57. Piore, M.J. Birds of Passage: Migrant Labor and Industrial Societies; Cambridge University Press: Chambridge, UK, 1979.

58. Becker, G.S. The Economics of Discrimination; University of Chicago Press: Chicago, IL, USA, 2010.

59. Block, F; Evans, P. The State and the Economy. In The Handbook of Economic Sociology; Princeton University Press: Princeton, NJ, USA, 2010; pp. 505-526.

60. Kalev, A.; Dobbin, F.; Kelly, E. Best practices or best guesses? Assessing the efficacy of corporate affirmative action and diversity policies. Am. Sociol. Rev. 2006, 71, 589-617. [CrossRef]

61. Schmitz, H.P.; McCollim, E.M. Billionaires in Global Philanthropy: A Decade of the Giving Pledge. Society 2021, 1-11.

62. Hockerts, K.; Wüstenhagen, R. Greening Goliaths versus emerging Davids-Theorizing about the role of incumbents and new entrants in sustainable entrepreneurship. J. Bus. Ventur. 2010, 25, 481-492. [CrossRef]

63. Van Der Vlist, A.J.; Folmer, H. Environmental technology and management in Dutch horticulture. Int. J. Environ. Technol. Manag. 2009, 11, 207-217. [CrossRef]

64. Rennings, K.; Ziegler, A.; Ankele, K.; Hoffmann, E. The influence of different characteristics of the EU environmental management and auditing scheme on technical environmental innovations and economic performance. Ecol. Econ. 2006, 57, 45-59. [CrossRef] 
65. Heras, I.; Arana, G. Alternative models for environmental management in SMEs: The case of Ekoscan vs. ISO 14001. J. Clean. Prod. 2010, 18, 726-735. [CrossRef]

66. Jackson, T. Prosperity without Growth: Foundations for the Economy of Tomorrow; Taylor \& Francis: Oxford, UK, 2016.

67. Jackson, T. Post Growth: Life After Capitalism; John Wiley \& Sons: Hoboken, NJ, USA, 2021.

68. Mercure, J.-F.; Sharpe, S.; Vinuales, J.E.; Ives, M.; Grubb, M.; Lam, A.; Drummond, P.; Pollitt, H.; Knobloch, F.; Nijsse, F.J. Risk-opportunity analysis for transformative policy design and appraisal. Glob. Environ. Chang. 2021, 70, 102359. [CrossRef] 